\title{
Prácticas filológicas y literarias en el Anacreón castellano de Quevedo
}

\author{
Sigmund MÉNDEZ \\ Universidad de Salamanca \\ sigmundmendez@yahoo.es
}

Recibido: $12-12-2012$

Aceptado: $7-12-2013$

\section{RESUMEN}

Este artículo estudia algunos aspectos del Anacreón castellano de Francisco de Quevedo con relación al original publicado en 1554 y las traducciones latinas de Henri Estienne y Élie André. En primer término, analiza algunos loci difíciles o irregulares en sus propias versiones o discutidos por el autor en sus notas para reconsiderar el alcance de sus labores como filólogo no profesional y de cara a la polémica sobre su helenismo. Seguidamente, tomando en cuenta las peculiaridades de los ejercicios de traducción vigentes en el Renacimiento, presenta una revisión ordenada de las distintas estrategias literarias que pueden dilucidarse tras las amplificationes de sus textos, que permiten valorar la índole misma de sus versiones y el sitio y función que tienen dentro de su obra poética.

Palabras clave: Quevedo, Anacreón castellano, Anacreontea, traducción en el Renacimiento, paráfrasis, amplificatio, tradición clásica

\begin{abstract}
This article studies some aspects of Francisco de Quevedo's Anacreón castellano considered with relation to the original published in 1554 and the Latin translations of Henri Estienne and Élie André. Firstly, some difficult or irregular loci in Quevedo's versions or argued in his notes are examined in order to review the scope of his labours as a non-professional philologist and with regard to the question of his Hellenism. Next, and taking into account the Renaissance practices of translation, the analysis offers an ordered revision of several literary strategies that can be elucidated in the multiple amplificationes in his texts, making possible to evaluate the nature of these versions and the place and function that they have in Quevedo's poetic work.
\end{abstract}

Keywords: Quevedo, Anacreón castellano, Anacreontea, translation in the Renaissance, paraphrase, amplificatio, classical tradition

\section{INTRODUCCIÓN}

En 1554 vio la luz la princeps de los Carmina Anacreontea, editada por el helenista francés Henri Estienne (Henricus Stephanus) bajo la supuesta autoría del poeta Anacreonte, acompañada de anotaciones y traducción latina parcial. El «descubrimiento» motivó un vivo entusiasmo y una amplia recepción europea. Dio lugar a una pronta 
versión latina en 1556 de los poemas ofrecidos por Estienne, a cargo de Élie André (Helias Andreas), cuyos textos aparecen alternando con los de éste en ediciones posteriores. Medio siglo más tarde, Francisco de Quevedo realizó en España la primera «traducción» de las cincuenta y cinco odas y dos fragmentos adicionales titulada Anacreón castellano, con paráfrasi y comentarios, dedicada en 1609 al duque de Osuna y que circuló de manera manuscrita, no siendo impresa sino hasta 1794.

El Anacreón castellano tuvo una difusión limitada y no exenta de accidentes y ha dado pábulo a una intermitente y a veces enconada polémica, que se remonta a la diatriba gongorina contemporánea (contraria a los elogios de Justo Lipsio, Vicente Mariner, González de Salas y Nicolás Antonio sobre sus conocimientos humanísticos), ${ }^{1}$ o la censura neoclásica de Flórez Canseco. ${ }^{2}$ En el siglo xx, tras la opinión más positiva de Castanien (1958), Sylvia Bénichou-Roubaud (1960) realizó una pormenorizada compulsa con las versiones latinas de Estienne y André redundando en un juicio lapidario sobre el helenismo de Quevedo. Con posterioridad, Enriqueta de Andrés ha atemperado tan tajante dictamen, ${ }^{3}$ y Lía Schwartz $(1999,2003)$, Francisca Moya del Baño (2006a, 2011) y Aurelio Pérez Jiménez (2011) han dedicado también notables artículos a la obra que lo contradicen o atenúan y revaloran otras de sus características.

A tal propósito, y en sintonía con estudios sobre las versiones renacentistas de los Anacreontea, se han destacado los criterios particulares, muy distintos en efecto de los vigentes en la filología decimonónica y sus sucesoras, que operan en la teoría y la praxis de la traducción en los siglos XVI y XVII. ${ }^{4}$ "Traducir» un texto era a veces visto como una operación sucedánea y azarosa, un ejercicio escolar o un acto preparatorio o el franco hipotexto para la obra propia del escritor. Su práctica estaba escollada entre criterios y preocupaciones diversos, cuyos extremos van del servilismo y la fidelidad a la imitación y la emulación, y en los que a veces primaban la falta de método y los descuidos y osadías de una «sublime inconsciencia». ${ }^{5}$ Ciertamente, para los humanistas parte medular del sentido en el estudio e imitación de los clásicos radicaba no sólo en la preservación de las obras e ideales antiguos, sino que implicaba a su vez un acto de continuidad, un modo de insuflarle vida nueva al pasado para que adquiriese plena significación en el presente (tal fue el sentido de la idea cultural de la rinascita). De hecho, a sus propios ejercicios de imitación responde precisamente el corpus que componen las Anacreónticas, escritas probablemente entre las épocas imperial y bizantina (en particular aprox. siglos I-VI d. C.), ${ }^{6}$ bajo el influjo vario de la poesía lírica de corte simposíaco y el epigrama helenístico, y reunidas bajo la figura cuasi mítica de Anacreonte, el anciano poeta cantor de los placeres del amor y del vino. Su modalidad compositiva principal es la imitatio, desprovista del carácter de

\footnotetext{
${ }^{1}$ Schwartz (1999: 295-296, n. 3).

${ }^{2}$ Hernando (1975: 185-188).

${ }^{3}$ Ante las opiniones contrapuestas sobre el profundo saber o la ignorancia casi total, dicha autora opina que «la realidad está en el medio» (Andrés, 1988: 185).

${ }^{4}$ Schwartz (2001: 1177-1180).

${ }^{5}$ Véase Lindeman (1981).

${ }^{6}$ Brioso Sánchez (1970: 46).
} 
rivalidad de la aemulatio. ${ }^{7}$ No sucede lo mismo, sin embargo, entre los traductores renacentistas y barrocos. Menos aún si se escribe, como declara Quevedo, de acuerdo con los paradigmas de la paraphrasis ${ }^{8}$ y lo que, según criterios de la época, era válida esfera de acción para un parafraste ${ }^{9}$ que podía satisfecho llegar a asumir que ha «mejorado» el original. ${ }^{10}$ Son libertades que, en mayor o menor medida, pueden corroborarse aun en «traductores» (Belleau, Villegas) u otros tantos autores de la época y aun posteriores que «imitaron»o «parafrasearon a Anacreonte» (de Ronsard o Du Bellay a Abraham Cowley, el conde de Rochester John Wilmot o Meléndez Valdés), o bien, entre quienes compusieron (como Sidney, 1985: 143) «in Anacreon's kind of verses».

\section{ALGUNAS PARTICULARIDADES FILOLÓGICAS}

Para comprender y valorar la naturaleza y alcances del Anacreón quevediano es indispensable contrastarlo con las versiones de Estienne y de André, que el propio autor declara haber manejado ${ }^{11}$ y que evidencian haberle sido en no pocos casos fundamentales. Dicho examen lo ha realizado ya Bénichou-Roubaud (1960: 63-68), pero es necesario revisar varios casos. Cabe en primer término destacar los sin duda visibles y abundantes pasajes donde Quevedo se basa en los textos latinos intermedios. Algunas muestras:

\footnotetext{
${ }^{7}$ En efecto: «the anacreontic poet would never 'break a lance' on Anacreon - his model is for imi-

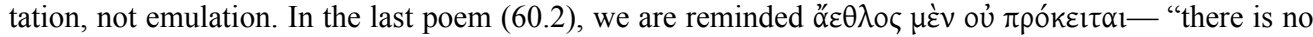
contest here"» (Rosenmeyer, 1992: 71).

${ }^{8}$ Según perfilan las célebres indicaciones de Quintiliano: Neque ego paraphrasin esse interpretationem tantum uolo, sed circa eosdem sensus certamen atque aemulationem. Ideoque ab illis dissentio qui uertere orationes Latinas uetant quia optimis occupatis quidquid aliter dixerimus necesse sit esse deterius (Inst. 10.5.5). Antes, en los ejercicios recomendados por el retórico, aparece prescrita la paráfrasis como un momento dentro de un proceso de paulatino abandono de la sujeción al modelo (como ejemplo, las fábulas esópicas): tum paraphrasi audacius uertere, qua et breuiare quaedam et exornare saluo modo poetae sensu permittitur (Inst. 1.9.2).

${ }^{9}$ Por ejemplo, en el Renacimiento francés Du Bellay indicó el desde su perspectiva necesario antiliteralismo en las versiones en lenguas vernáculas, en una argumentación articulada según una jerarquía que abarca al «traducteur» y al «translateur», cuyos trabajos tienen un sentido más «pedagógico», y el "paraphraste» y el «imitateur», con mayor libertad para rehacer un texto bajo otros paradigmas estéticos. Véase O’Brien (1995: 72). Por ello también en efecto, la versión de Villegas puede considerarse, como indica Schwartz (2001: 1185), «más "escolar"».

${ }^{10}$ Según declara el propio Quevedo (1958: 516a) en la España defendida sobre el valor de la lengua española, que no hace desmerecer los originales grecolatinos, y sus propias aportaciones que incluyen «a Anacreón mejorado en castellano por mí».

${ }^{11}$ También deja ver que tuvo contacto con la versión francesa de Remy Belleau (1556) y la latina de Eilhardus Lubinus (1597), pero, como ya destacara Bénichou-Roubaud (1960: 59 y 67), Quevedo recurre sobre todo a Estienne y André. En cualquier caso, según ha subrayado Moya del Baño (2006a: 701) respecto de los severos censores del poeta: «lo que no hacía — me atrevería a decir nunca — era engañar a sus lectores».
} 


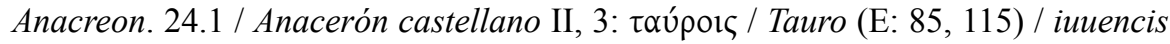

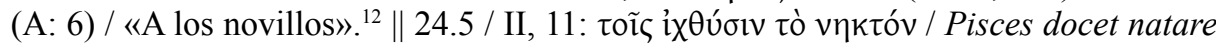
(E: 86, 115) / Vim piscibus natandi (A: 6) / «al mudo nadador alas y brío» (modificando

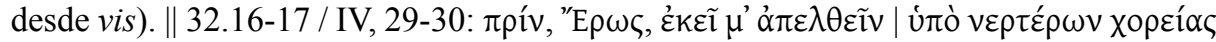
/ Etenim priusquam ad Orci | Rapiar nigri choreas (E: 88, 119 y 121) / Libet, antequam choreas | Acherusias petamus (A: 9) / «porque antes que yo baje | a los reinos del Orco».

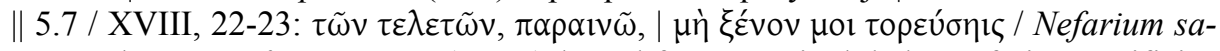
crorum | ritum aufer externum (A: 19) / «y el forastero rito | de los nefarios sacrificios deja». || El texto correspondiente a Anacreon. 18.10-11: Agedum Bathylli ad vmbram | Statue arborem virentem (A: 22) que da «A la sombra de Batilo | pon, pintor, un árbol

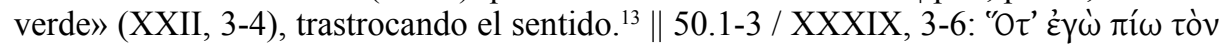

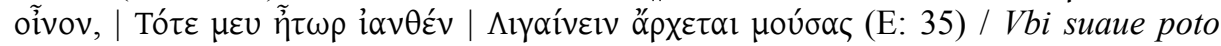
vinum | Animo repente laeto / Celebro nouem Camoenas (A: 35) / «Luego que el vino süave | despacio y con gusto bebo, | las nueve Musas, alegre | y de repente, celebro», donde del calco sólo lo salva la substitución de Camenae por «Musas»; etcétera.

Menos frecuentes, pero con todo reveladoras, hay también palabras y estructuras que demuestran cómo Quevedo también en ocasiones se acerca más que los propios traductores latinos al original griego. En respuesta al trabajo de Bénichou-Roubaud, de modo reciente Pérez Jiménez (2011) ha detectado con acierto la mayor parte de esos casos específicos de correspondencia léxica o gramatical; valga presentar varios ejemplos representativos:

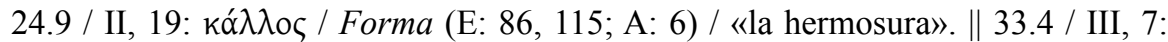

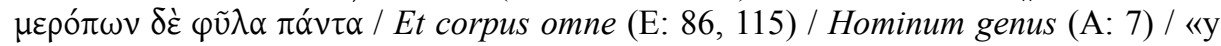

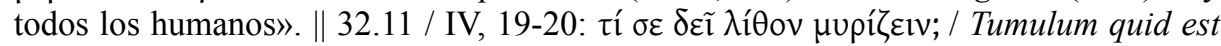
quod vngas $(\mathrm{E}: 88,119)$ / Lapidi quid addis vnguen? (A: 8) / «¿De qué sirve a la piedra | dar bálsamo oloroso [?]».|| En 7.1-2 / XI, 3-4, se apega como Estienne al texto griego y no copia el verso inicial añadido por André (His vocibus procaces, A: 14). || 8.1-2 /

${ }^{12}$ Se cita el número del poema y el texto griego de los Anacreontea según la edición de West (1993) $\mathrm{y}$, cuando son pertinentes, las variantes de la princeps de Estienne (1554) = E; y número y líneas del poema correspondiente y los comentarios de Quevedo (1985: 239-344) por la edición de Blecua. Se abrevia para las citas latinas: $\mathrm{E}=$ Estienne $(1554,1560)$ y $\mathrm{A}=$ André $(1556)$ y número de página. Se citan por su número y versos otros poemas de Quevedo (1968) de acuerdo con la edición de Blecua de la Poesía original.

${ }^{13}$ El notable error fue duramente censurado por Flórez Canseco y apuntado por Bénichou-Roubaud (1960: 67, n. 36). Quevedo desarrolla la descriptio como un poema ecfrástico a la manera de otras odas (XVII, XVIII, XXVIII, XXIX, XLIX); sin embargo, ya en Belleau (1556: 29) encontramos: «Fai moi pres ce iouuenceau | Vn ombrageus arbrisseau», que quizás ha «inducido» la incorrecta lectura quevediana de la traducción latina, desvío tal vez favorecido por razones moralistas y que en todo caso tiene sus dificultades de origen. Villegas (1941: 187) usó la corrección de Estienne ( $\beta \alpha ́$ $\theta v \lambda \lambda \varepsilon)$, pero apoyándose también en André: «Ea, dulce Batilo, | busca, busca la sombra, | y escoge un árbol verde» (23, 2-3). Nótese que André leyó bien $\beta \alpha \theta u ́ \lambda \lambda$ ou y no dicha enmienda, que modifica el sentido; pero su opción no a pocos resultó incomprensible. Todavía a Pauw (1732: 93, n. ad XXII, 3) le parecía un claro error: Andreas Interpres hic in Versione Latina totam Odarii Scenam invertit: Id vident omnes. An hominem forte fefellit istud scripturae vitium? Y aun Degen (1808: 59-60) consideraba que mantener $\beta \alpha \theta u ́ \lambda \lambda$ ov y asumir su representación como árbol era ingrata et sane monstrosa imago. 


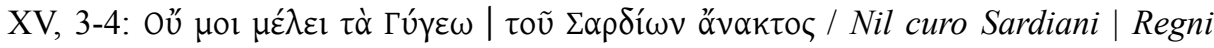
Gygen potentem (E: 93, 135 y 137) / Nil Sardium potentem | Curo Gygem (A: 17) /

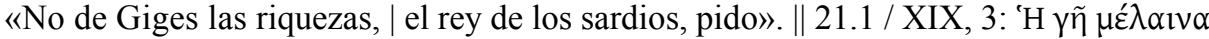
Tível / Foecunda terra potat (E: 95, 141) / Terrae bibunt feraces (A: 20) / «Bebe la

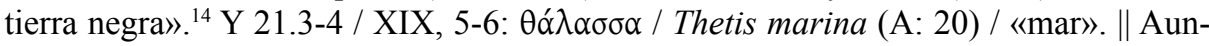
que basado en Estienne, varias semejanzas léxicas y gramaticales con el texto griego

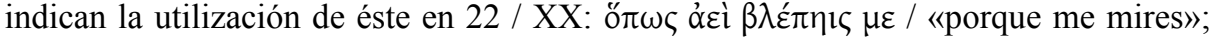

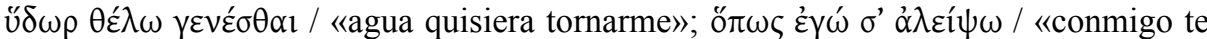

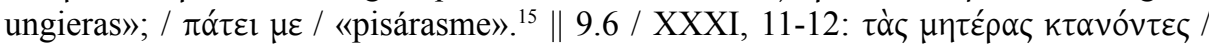
Vterque matricida (E: 101, 159) / Vterque matre caesa (A: 29) / «habiendo [...] | sus propias madres muerto». \| Con claros añadidos y uso de la versión latina también si-

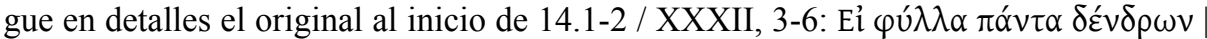

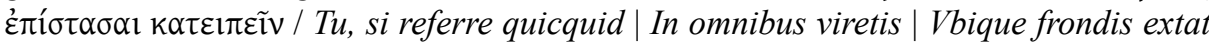
(A: 30) / «Si tú pretendes contar | las hojas que Primavera | con verdes manos reparte |

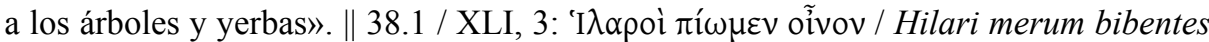

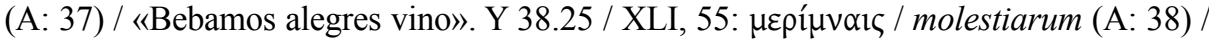

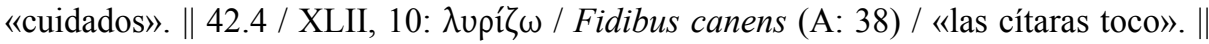

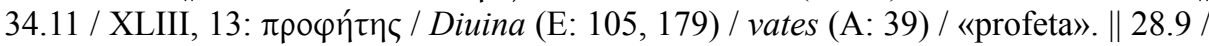

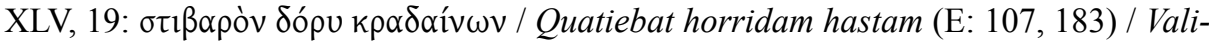
dam vibrabat hastam (A: 41) / «vibrando una gruesa lanza». || 27.5-6 / LV, 15-16: غ̇үì

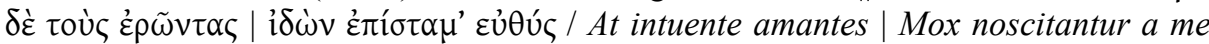
(E: 110, 199-200) / Nosco videns amantem (A: 50) / «Pero yo, en mirando un hombre, | luego conozco si ama»; etcétera.

Si bien la general predominancia en el uso de las intermediaciones latinas es notoria, dichos ejemplos y otros tantos mostrados por Pérez Jiménez dan aceptable sustento al helenismo de Quevedo y ponen a la vista la contextura plurívoca de sus versiones. El poeta no engaña al lector y en efecto prueba que «miró» el texto griego editado por Estienne y que en varias ocasiones ha transladado directamente de él. De tal forma, cabe asumir que su trabajo como traductor o parafraste es irregular y acaso desarrollado en períodos distintos y con criterios y abordajes divergentes. Hay versiones más literales y otras libérrimas; a veces se aproxima de modo directo al original y en un

${ }^{14}$ Por ejemplo, Villegas (1941: 185) sigue en su texto a los traductores: «Bebe la tierra fértil» $(20,1)$.

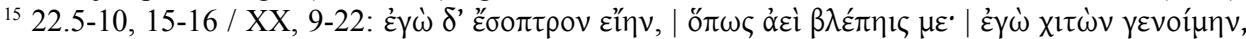

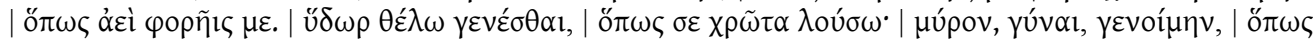

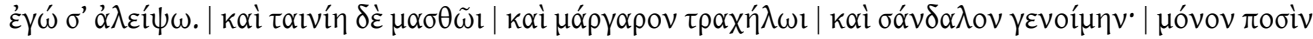

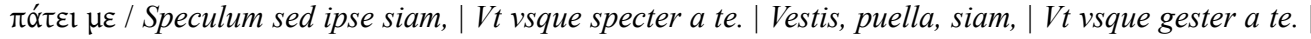
Liquor esse purus optem, | Lauem tuos vt artus. | Vnguentum et esse molle, | Artus tuos vt ungam. | Aut sim monile collo, | Strophium aut tuis papillis. | Sim calceus, tua me | Saltem terasque planta (E: 95-96, 143) / Speculum forem sed ipse, | Quod semper intueris. | Vestis forem decora, | Vt semper induas me. |O si latex perennis $\mid$ Fiam, lauemque totam. | Te, lux mea, vt linam, sim | Nardus libens odora. | Sim falcia et papillis. | Collo vnio decenti. | Plantisque mollicellus $\mid$ Sim calceus tenellis, |Vt ambulans teras me (A: 2021) / «sólo volverme tu espejo, | porque me mires, quisiera. | Quisiera ser vestidura, | porque me trujeras puesta; | agua quisiera tornarme, | por lavar tus manos bellas. | Ungüento quisiera ser, | porque conmigo te ungieras; | o, por estar en tu cuello, | ser el collar que le cerca. | Quisiera ser el corpiño | que tus pechos encarcela, | o, a lo menos, tu chapín: | pisárasme así soberbia». 
mayor número de poemas adopta como base una de las traducciones latinas; pero asimismo puede «sintetizar» o resolver algún pasaje con un simultáneo uso de éstas ${ }^{16}$ o conjuntándolas con el texto griego. ${ }^{17}$ Por tal razón, en el estudio del Anacreón castellano no es pertinente simplificar bajo una sola fórmula tan proteicas modalidades de «traducción» y se impone, por encima de la evaluación general, el análisis casuístico.

Hay ciertos elementos especialmente significativos para ponderar las operaciones filológicas de Quevedo y su pertinencia, que merecen una atención focalizada. Se trata de algunos detalles que evidencian lecturas propias, varias sobre pasajes difíciles en donde el poeta atreve conjeturas críticas e incluso pretende polemizar con Estienne para sustentar sus decisiones. ${ }^{18}$ De ellos los más notables son:

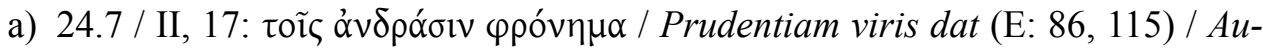
daciam viris (A: 6) / «A los hombres dio esfuerzo y osadía». Quevedo prefiere la interpretación de André y la razona en su nota. En su argumentación incluye una cita de Homero (Il. 2.671-673), cuya parte medular no es homérica (Forma mulieres ornat, vi-

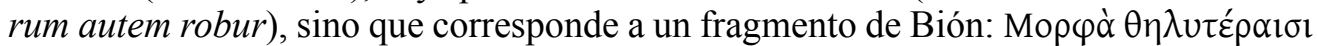

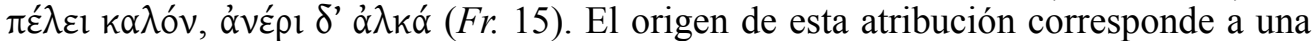
lectura errónea o manipulada de Estobeo, quien conserva el texto citado junto con el de la Ilíada (Stob. 4.21a.3-4). ${ }^{19}$

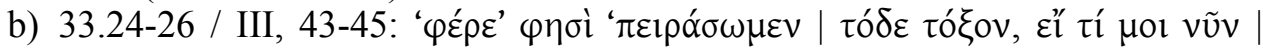

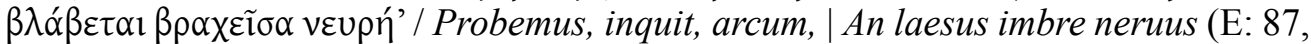
117) / Libet, inquit, experiri: | Madet imbre nanque neruus (A: 8) / «Probemos, dijo, el arco, | por si la cuerda floja | mojada no dispara». Es conjeturable que la substitución de $\beta \lambda \alpha ́ \beta \varepsilon \tau \alpha \iota$ / laesus por «floja» para la cuerda dañada la condicione la rima y sea «deducida» del contexto, mientras que «mojada» queda por el participio $\beta \rho \alpha \chi \varepsilon \tilde{\tau} \sigma \alpha{ }^{20}$

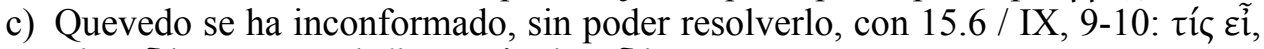

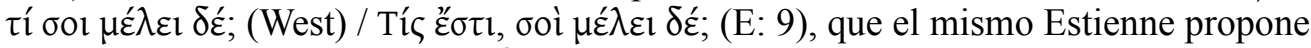
en su nota que podría leerse Tí $\delta$ ' y que traduce como Eho, quid istud ad te? (E: 89, 127; Quis est? rei quid autem? A: 12). Luego Quevedo, asumiendo que es respuesta de la paloma (leyendo desde la tra-

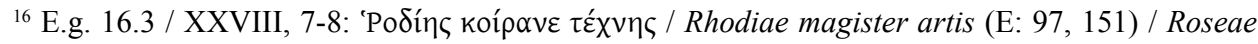
magister artis (A: 25) / «Y pues de la rodia arte / y la rosa, eres maestro».

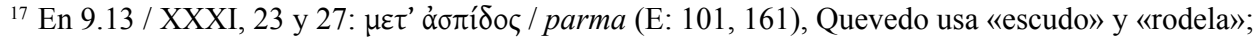
para 27.8 / LV, 22 y $26 \psi v \times$ ń, / cor (E: 110, 201; A: 50), en las amplificaciones quevedianas aparecen tanto «alma» como «corazón»; etcétera.

${ }^{18}$ Aunque es obvio, como subraya Pérez Jiménez (2011: 108), que «su competencia se oriente más a disquisiciones de tipo literario que propiamente lingüístico o ecdótico».

${ }^{19}$ La secuencia de las citas y el texto latino corresponde (con alguna errata y omisión) al siguiente en la versión de Gessner (1543: 380): Nireus et iam ex Symo ducebat tres naues aequales | Nireus Aglaiae filius, et Charopi domini, | Nireus qui formosissimus uirorum ad Ilium uenit. | Forma mulieres ornat, uirum autem robur (Sermo LXIII, «Laus Pulchritudinis»).

${ }^{20}$ Por el contrario, Bénichou-Roubaud (1960: 67) intentó usar en provecho de su tesis el pasaje, «interpretando» a Estienne: «"si el nervio, encogido" [...] El $\beta \rho \alpha \chi \varepsilon \tilde{\imath} \sigma \alpha$ fue interpretado correctamente por Estienne en el sentido de "encogido por la lluvia"». No hay por supuesto nota de Estienne al respecto, ni el original ni el laesus explicita tal lectura, lo que sugiere que dicha crítica confundió $\beta \rho \varepsilon ́ \chi \omega$ con $\beta \rho \alpha \chi v ́ v \omega$ ( $\beta \rho \propto \chi \cup ́ \varsigma)$, con base posiblemente en Villegas (1941: 173): «por si el nervio se encoge» $(4,42)$. 
ducción: Eho, quid istud ad te [attinet]? / quid id attinet ad te?: Pl. Per. 284) escribe: «Pregunto yo: por dicha, | saberlo ¿qué te importa?»;21 que en su nota explica como «"¿Quién eres, que te metes en esto?"». Quizás a su favor sólo puede indicarse que, «por intuición», ha creído en la necesidad de mantener tís y virtualmente «vislumbrar» parte de lo que sería la solución que a partir de Tollius propuso Brunck (1786: 14) y aceptada por West. ${ }^{22}$

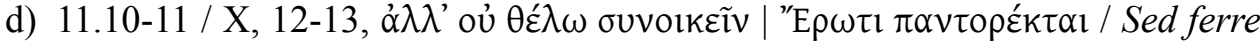
nolo Amorem | Domi omnium appetentem (A: 14) / «sino por no tener un dios consigo | de la paz de los hombres enemigo». Quevedo, que parece no haberse satisfecho con la versión de André, translada de modo claramente libre e interpretativo, pero no del todo

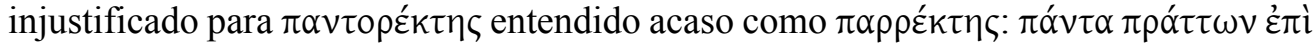

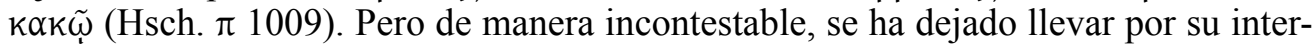
pretación de lo que el poema «debe» decir (que se trata de un encantamiento referido a la obtención del favor del amado), ${ }^{23}$ y pasando por encima del texto y traducción ( $\mu \varepsilon$ | $\pi u ́ p \omega \sigma o v /$ fac calescam), asume un presente de tercera persona («que ardiente fuego sin piedad me abrasa») y un tercer sujeto en una desiderativa sin sustento textual («que me quiera y admita») como fin de la petición-amenaza dirigida al dios.

e) En la nota correspondiente a 49 / XXVII, traduce unos versos de Teócrito (29.12): «El vino también dice las verdades, | como tú, niño hermoso: | y por esto conviene a los borrachos $\mid$ nombre de verdaderos...» (58-61). En este caso, Quevedo basa su versión en la que equivocadamente hizo el profesor de griego de Wittenberg Vitus Winshemius (1558: 292; Vinum, o chare puer, dicit vera: | Et nos ebrios oportet veraces esse), notada por Estienne. ${ }^{24}$ Claro que la añadida función comparativa («como tú niño hermoso») que le da Quevedo es impropia ${ }^{25}$ (en algunas lenguas el vocativo pueda llegar a cumplirla), aunque no afirma que lo sea gramaticalmente, sino que adapta así lo que supone una función intensificativa y apelativa. Con ello deja ver el modo en que opera en sus traducciones, donde sobre la morfosintaxis se impone la semántica determinada por la interpretación comparatista (en este caso, los «paralelos» castellanos) o ciertos esquemas estéticos o ideológicos.

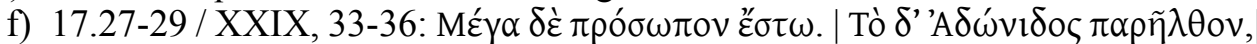

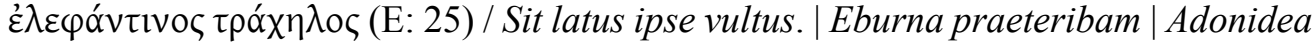
colla (E: 100, 157) / At amplus esto vultus. | Sed eburna praeteribam, | Adonidisque

${ }^{21}$ En la versión de Belleau (1556: 18): «LA COLOM. Que t’en chaut!». En Villegas (1941: 177): «¿Pues a ti qué te importa?» $(10,5)$.

${ }^{22}$ Caso curioso, anotado por Astrana Marín (1952: 757, n. 1), es en este mismo poema el deturpado verso 31, donde la conjetura پ̈ßporৎ de Rose (1890: 17) parece en «caso estupendo» presentirla Quevedo en su versión («con mis alas süaves»). Hay otras «adivinaciones» quevedianas, como en 5, 1 / XVIII, 3-5,

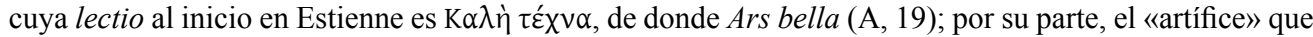


códice parisino que aceptan las ediciones modernas.

${ }^{23}$ Quevedo piensa en Theoc. 2.28-29; Verg. Ecl. 8.80-81; Hor. Epod. 17.76.

${ }^{24}$ Valde autem inepte ista reddebantur in ea ad verbum interpretatione quae praecessit quam habes hic: isto videlicet modo, Vinum, o chare puer, dicit etiam vera. quasi $\lambda \varepsilon ́ \gamma \varepsilon \tau \alpha$ l possit ponit pro $\lambda \varepsilon ́ \gamma \varepsilon l$. (Estienne, 1579: s.p. [Emendationes, ad. p. 244]).

${ }^{25}$ Cf. Bénichou-Roubaud (1960: 70) (quien parece no haber entendido bien los problemas implícitos en el texto). 
colla (A: 27). Quevedo apunta que para este pasaje existe una interpretación diferente, indicada por Daniel Heinsius en sus notas a Silio Itálico, que leyó no el aoristo $\pi \alpha \rho \tilde{\eta} \lambda \theta$ ov sino como el participio $\pi \alpha \rho \eta \lambda \theta$ óv y reordenando el pasaje tradujo: Facieque latus esto | Superansque Adonideam. ${ }^{26}$ Es plausible caso el que Quevedo tuviese en cuenta esta corrección, desatendida en las ediciones modernas, dando muestra de sus amplias lecturas. ${ }^{27}$ Sin embargo, aunque dice entender como Heinsius, tradujo de un modo distinto: "Alegre y desenfadado | le pinta el rostro; haz que venza | su cuello al de Adonis blanco, | y harás que de marfil sea» (33-36). Dejando de lado el error del verso 27 ( $\mu \varepsilon^{\prime} \gamma \alpha$ pro $\mu \varepsilon \tau \alpha$ ), que ha extraviado las diversas traducciones, parece que el poeta ha operado, como a menudo ocurre, según su libérrima voluntad. ${ }^{28}$ Pero aun dentro de la desajustada versión, es de notar que - sive felici casu sive ope ingenii reperta- Quevedo parece en realidad entender $\pi \alpha \rho \varepsilon \lambda \theta \omega \omega \nu$ y haberse así anticipado a la emendatio Salmasiana: $\tau o ̀ v ~ ' A \delta \omega ́ v 1 \delta o \varsigma ~ \pi \alpha \rho \varepsilon \lambda \theta \omega ́ v$, que se ha impuesto en las ediciones modernas, y a la propia traducción que la acompaña: Cervix eburnea vincens | Adonidis candore cervices, ${ }^{29}$ prolija de un modo en algo semejante a la suya (candore / «blanco»).

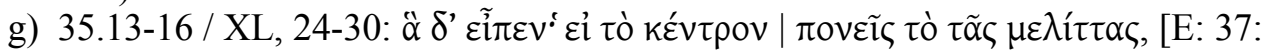

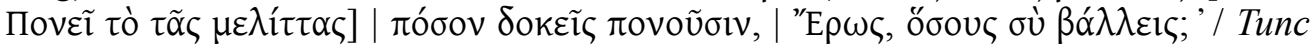
illa, Apis si acumen | Tantum facit dolorem, | Quantum putas dolere (Quantum dolere credis) | Quos tu feris Cupido? (E: 104-105, 173) / At si, inquit illa, fili | Apis perurit ictus, | Quantum putas laborent, | Quos tu feris sagittis? (A: 36) / «-Mas la diosa | respondió:-Si una serpiente | de cuerpo y fuerza tan poca | puede dar dolor tan grande | desarmada, humilde y sola, | ¿cuánto mayor le darás | tú con las flechas que arrojas?». La primera parte de la condicional lleva a cabo, al parecer, una intensificación de contraste (la nimiedad de la abeja contra el poder del dios). En la segunda, Quevedo arriesga una interpretación distinta que, como declara su nota, se basa en una elucubración comunicada por el poeta andaluz Francisco de Rioja, ${ }^{30}$ quien quiso

${ }^{26}$ Heinsius (1600 [anexo: Crepundia Siliana, 1601]: 402-403) (n. ad Sil. 6.297). Véase Moya del Baño, (2011), quien destaca que la corrección de Heinsius es atendible, e incluso ventajosa por conservar la lectura del manuscrito. En general, ha sido olvidada por los editores modernos, pero por ejemplo Paul Colomiès (1669: 268) prefirió esta lectura del $\pi \circ \lambda \nu \mu \alpha \theta \varepsilon \dot{\sigma \tau \tau \alpha \tau o \zeta ~ H e i n s i u s ~ s o b r e ~ l a ~ d e ~ S a l m a s i u s . ~ L e e r i ́ a s e ~}$

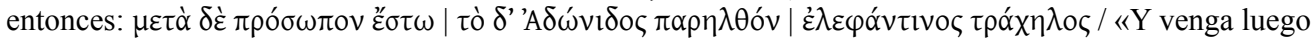
del rostro | (que aventaja en verdad al de Adonis) | ebúrneo cuello».

${ }^{27}$ Como bien ha destacado Moya del Baño (2011: 324): «Lo que llamamos suerte deriva de una de las grandes virtudes de Quevedo, su amor a los libros, su amor a los clásicos latinos y griegos; su gusto por la lectura, su conversación, como dice, con los difuntos».

${ }^{28}$ Bénichou-Roubaud (1960: 71) sostenía, de modo previsible, sobre la enmienda de Heinsius que Quevedo «parece no haberla entendido del todo». Pero teniendo a vista la traducción del alumno de Josephus Justus Scaligerus esto no resulta muy verosímil. Nótese que Quevedo se contradice en la nota al decir que «leo diferentemente que todos el original», y luego «leo con Daniel Hensio», lo que deja abierta la posibilidad (aunque no lo clarifica) que leyese en efecto «a su propia manera» el pasaje. Heinsius separa el verso 29, que no traduce («en el que, lógicamente, se debe sobreentender ह̌ $\sigma \tau \omega »$, como ya sugería Estienne en su nota, es decir eburneum collum esto, según Moya del Baño, 2011: 323).

${ }^{29}$ Salmasius (1640: 664) (n. ad Ach.Tat. 6.3.1).

${ }^{30}$ Pocas noticias hay sobre el saber de helenista de Rioja. Quedan, además del testimonio de Quevedo, los elogios de Lope de Vega (1609: 495v): «Rioja propio en el idioma estraño, | Dilate la Romana y 


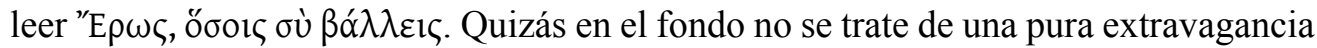
si se considera, en la secuencia lógica de las frases, un desequilibrio respecto de $\tau$ ò

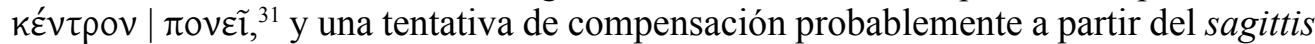
en la traducción de André. Cabe además recordar que Michelangeli (1882: 200) quiso

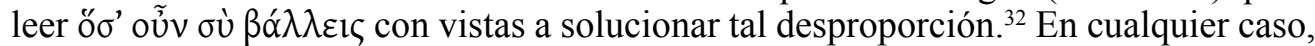
Quevedo, que ha comprendido sin dificultad alguna la lectura de Estienne (lo muestra su traducción literal de ella), ${ }^{33}$ permite ver que su modo de leer los textos suele obedecer menos a una pura imprudencia o precariedad lingüística que, valga decir, a su «punto de vista» ${ }^{34}$ y personal manera de querer dilucidarlos (en pasajes ciertamente discutibles aun para helenistas profesionales posteriores), y transformarlos de acuerdo a criterios diversos.

h) Otros casos de desacuerdo entre los textos precedentes y la versión quevediana son llamativos y corroboran, por encima de una supuesta «ignorancia», las conscien-

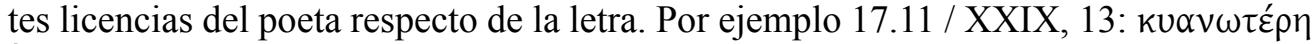

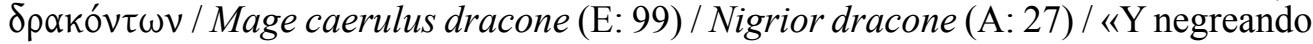
en torno». Sin embargo, en su nota Quevedo da otra traducción más ajustada: «Y más negro que un dragón» (62), discutiendo luego la cualidad adscrita al «dragón» y la pertinencia del color y de la comparación para las cejas de Batilo. ${ }^{35}$ También, por lo que toca al Fragmento II, 2-5 (= Anacr. PMG 395.1-2), la traducción es muy libre, aunque

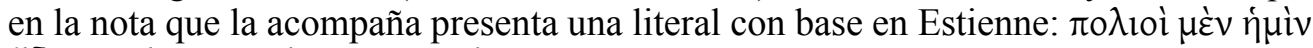

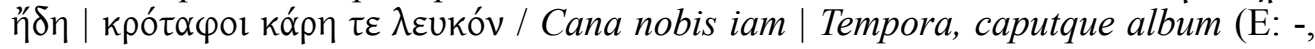
209) / «Viendo que ya mi cabeza | siente los hurtos del tiempo, | que no hay guedeja en mis sienes | que me acuerde el color negro» / «Ya tengo canas las sienes, y la cabeza

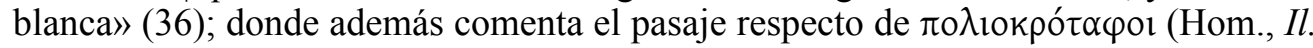
8.518), recordado en el prólogo en griego de Estienne (E: *3v), según la explicación de Alejandro de Afrodisias (Pr. 1.1).

Griega historia», y al margen «El lic. Rioja, gran Latino y Griego» (XIX). De modo documental subsiste la libre versión en silva de un texto de Libanio (Prog. XI, 11) conservada por Francisco Pacheco (2001: 429-430) y en un manuscrito corregido con posterioridad por el autor (Rioja, 1975: 300-302; 70-71 sobre sus relaciones con Quevedo).

${ }^{31}$ Tal la lectura del manuscrito, corr. Pauw: $\pi$ oveĩ que adopta West. Pero cabe apuntar que el mismo Pauw (1732: 161-162, n. ad XL, 14) aventuró una alteración mayor con su propio dativo (mostrando de

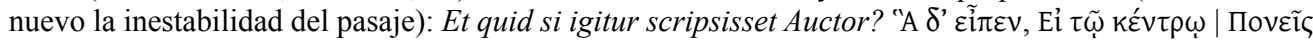
$\sigma \dot{\tau} \tau \tilde{\alpha} \varsigma \mu \varepsilon \lambda i ́ \tau \tau \alpha \varsigma$. Id certe non deterius visum fuisset mihi.

${ }^{32}$ Traduciendo: «Se una puntura | d' ape fa tanto male, | quanto, credi, ne fanno | quelle che, Amor, tu dài?» Y argumentó así su decisión: «La bontà della correzione mi pare evidentissima. Così non occorre

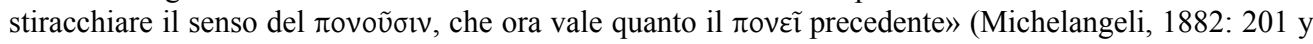
205). Amor?»

${ }^{33}$ «¿Si la punta de la abeja | causa tan grande dolor, | cuánto piensas que les duele | a los que hieres

${ }^{34}$ Castanien (1958: 575).

${ }^{35}$ Con referencia a Nic. Th. 438; Lyc. 1311; Fest. p. 67M (Dracones). 


\section{TRANSFORMACIONES TEXTUALES Y ESTRATEGIAS LITERARIAS}

Que el Anacreón castellano ofrece versiones muy desligadas y en no pocos pasajes disímiles o con versos añadidos es algo evidente, y el lector -al menos parcialmente - puede considerarse advertido por la calificación que dio el poeta a su texto de Paráphrasi. La definición de la voz en el Tesoro de Covarrubias (1943: 852)

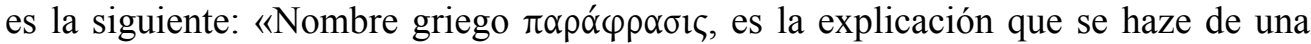
sentencia por otra, que es más fácil de entender y percebir; el tal intérprete se llama paraphrastes». ${ }^{36}$ En Autoridades se reproduce tal cual la definición de Covarrubias y la autoridad citada es el propio Quevedo (1958: 1421), en la Providencia de Dios: «Hasta aquí Tertuliano, cuyas palabras, sin la ensancha de alguna paráfrasi, no cupieran en mi pluma». Este comentario quevediano apunta a la dilatatio o la copia a manera de un procedimiento central de ella, ${ }^{37}$ y la sugiere de hecho, según puede inferirse, como un recurso a veces insalvable para traducir desde el latín (o el griego) que, por supuesto, se complica tratándose de translados en verso. ${ }^{38}$ De modo concomitante con este fenómeno, en el Anacreón se hacen presentes las contaminationes o allusiones respecto de otros textos, frecuentes en las traducciones del griego al latín o a las lenguas modernas en el Renacimiento y el Barroco, las cuales podían no ser efectuadas de manera directa, sino pasando a través del tamiz o la «interferencia» de otro texto, ya de una precedente traducción latina, ya pasajes de otras obras, bien de la literatura clásica o en lengua vernácula. De este modo, las versiones de Estienne o de André de las Anacreónticas aluden y echan mano directamente de subtextos de Plauto, Horacio, Ovidio u otros autores. Varios de estos poemas intermedios, por ejemplo ciertas odas horacianas, se asumían escritos bajo el influjo de Anacreonte, y a la mirada de los renacentistas resultaba válido servirse de ellos para tejer su propio texto anudando los elementos diversos de una larga tradición, sobre la cual entendían su labor humanística, no sólo como conservadores, sino también como continuadores. ${ }^{39}$

Ahora bien, en la labor de Estienne o del propio Quevedo, cuyas versiones están acompañadas de comentarios, el ejercicio de la traducción, la interpretatio, se articula

${ }^{36} \mathrm{Su}$ fin sería «allanar» o «clarificar» un texto, como implica la definición de Vives (1782: 228-229) en su De ratione dicendi: Paraphrasis est, quum ex una oratione alia dilatatur, breviter intertextis quae lucem adferant, ac proinde adjuvent intelligentiam, est enim tamquam viam paullo latiorem ac planiorem reddere, eadem vero tenere semper in sensis. Fin y características que en muchos casos no pueden adjudicarse a las versiones quevedianas, como tampoco en el apego textual que le sería implícitamente propio a la paráfrasis (quod a proposita phrasi, hoc est oratione, non discedat) y que proscribe las digressiones. Luego, Quevedo en el Anacreón se ajusta más al paradigma estético de la paráfrasis como aemulatio o certamen apuntados por Quintiliano (Inst. 10.5.5).

${ }^{37}$ Apuntado por Vives (1782: 230) como procedimiento contrario en la paráfrasis al del epitome: contractioni ac summae servit brevitas, ut paraphrasi copia.

${ }^{38}$ Según ha comentado Andrés (1988, 229): «Evidentemente Quevedo añade muchas palabras que no están en Anacreonte, pero recoge perfectamente las ideas que éste pretendió expresar que es todo lo que se puede pedir en una paráfrasis. Por otra parte una traducción en verso exige que el traductor tenga mayor libertad de expresión».

${ }^{39}$ Y no hay que olvidar la condición de «allusive text» de las propias Anacreónticas y sus múltiples elementos transtextuales (Homero, la lírica arcaica, Teócrito, los epigramatistas de la Anthologia Graeca, Platón, la novela, etcétera). Véase Rosenmeyer (1992: 151). 
tomando en cuenta el trabajo exegético sobre el texto, acto presente por supuesto, en mayor o menor medida, en toda traducción. ${ }^{40}$ En ello se pretendía sopesar tanto verba como sententiae y res, los referentes del discurso, cuya consideración está implicada al preguntarse por aquello que el autor buscó decir al momento de escribir y hacerlo comprensible a los receptores de un medio cultural diferente. En el caso de Quevedo, la paráfrasis del texto de las Anacreónticas se hace adoptando como base las versiones de Estienne y André y los comentarios de aquél que explican algunas decisiones filológicas al momento de traducir, a lo que se suman las diferentes allusiones y contaminationes respecto de otros textos y las interpretaciones y aun desvíos hermenéuticos realizadas por el propio traductor o parafraste.

Según lo dicho, la amplificación es una de sus características centrales y esto puede corroborarse de manera superficial en el Anacreón a través de la compulsa entre los versos del poema original y su correspondiente castellano, en donde a veces duplican o incluso triplican su número. ${ }^{41}$ Siendo amplias las licencias del traductor renacentista, y mayores aún las de un parafraste, bien puede corroborarse que el poeta se arrogó todas las que consideró pertinentes para mostrar su propia ubertas orationis. Resulta, sin embargo, oportuno estudiar los diferentes procedimientos y las conjeturables razones que motivan las modificaciones quevedianas. Es difícil establecer un deslinde preciso entre todas ellas, pues varias operan en un mismo caso simultáneamente. Con todo, es posible trazar una más o menos delineada cartografía.

a) Variaciones propiciadas por equívocos en la transmisión. Según se ha mostrado ya, en algunos casos el sesgo que aparece en las odas quevedianas proviene del original en la princeps o de la versión subsiguiente. Por ejemplo, la forma elegida en el texto de Estienne encauza el trasunto latino y la recreación de Quevedo: 18.8-9 / XXI,

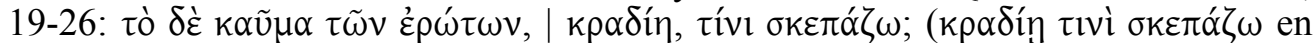
E: 19) / Penitissimos amorum | Aliter tego calores, | Aliquoque condo corde (A: 21) / «Que los diligentes | fuegos de Cupido | en otro lugar | los tengo escondidos. | Tengo reservado | para sus martirios | corazón diverso. | ¡Ved si los estimo!». Otro «enrique-

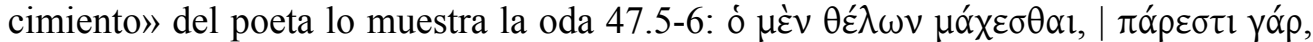

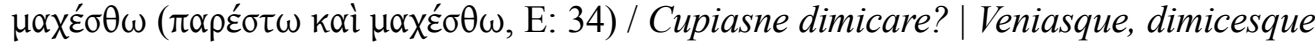
(E: -, 169), pasaje disputado donde la seguida petición de vino le permite a Quevedo la siguiente modificación: «Mas si probarme deseas | con luchar, ven y luchemos; enlacemos bien los brazos; | abracemos bien los pechos: | que no temeré tus fuerzas, | si mis amigos, primero, | me dan vino que me preste | ánimo, valor y esfuerzo. | No dio, llegando a la Tierra, | la Tierra tal fuerza a Anteo, | como a mí mi padre Baco | me da cuando a él me allego» (XXXVIII, 15-26). Leyendo de modo literal la supuesta

${ }^{40}$ Luego, en las prácticas renacentistas $-\mathrm{y}$ aun, en todo ejercicio de esta clase - hay que tener presente que «the translation is not a neutral medium; the reader is presented with poetry that has already been read and interpreted for him» (O'Brien, 1995: 148).

${ }^{41}$ Algunos ejemplos: VI / 43 se amplía de 16 a 28 versos; 10 / XV de 10 a 20; 5 / XVIII de 19 a 38; 40 / XXIIII de 9 a 24; 45 / XXV de 10 a 36; 19 / XXX de 9 a 24; 51 / XXXIV de 8 a 16; 47 / XXXVIII de 13 a $28 ; 38$ / XLI de 27 a 60; 42 / XLI de 17 a 56; 30 / XLIV de 10 a 32; 28 / XLIV de 17 a 36; 2 / XLVIII de 10 a 28; 57 / LI de 30 a 68; 59 / LII de 26 a 68. Aunque es necesario no olvidar que en otros casos, según ha puesto de relieve Pérez Jiménez (2011: 106), las diferencias numéricas son mucho menores. 
invitación al combate, que adopta de Estienne, desarrolla una amplificación «explicativa», puramente imaginaria, sobre los poderes del vino en un «hijo de Baco» con la referencia modélica del mito de Anteo.

b) Modificaciones y amplificaciones léxicas. Si bien es indudable que en muchos casos Quevedo parte de los poemas en sus versiones latinas, sus propias soluciones textuales no siempre son meros calcos y obedecen a sus propios procesos interpreta-

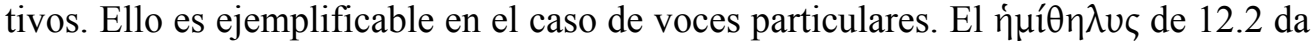
Gallus (A: 15) y en Quevedo «capón» (XIII, 3), ${ }^{42}$ de modo nítido el poeta entiende el sentido de fondo (los Galli de Cibeles y Catul. 63; Ov. Fast. 4.221-244) y el juego de palabras implícito en gallus (Mart. 3.81, 13.63). Otro caso es la diversa adjetivación en

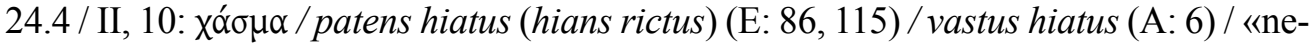
gra concavidad». Según muestra la nota de Estienne, Quevedo vierte hiatus por «concavidad»: Hiatum appellant etiam Latini (E: 65) / «También la llaman "concavidad" los latinos» (29). Pero el matiz distinto que le da es quizás más sutil y alusivo de lo que parece, pues pudo haber aplicado, en una curiosa asociación que permite la polivalencia de la voz, una variante que propuso Lipsius (1585: 39) para Propercio: «Et miser

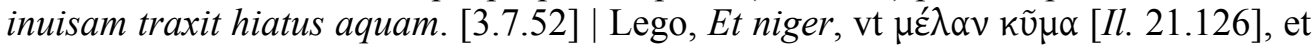
similia apud Homer.» ${ }^{43}$ En otras ocasiones, la amplificación funge a manera de glosa aclarativa; por ejemplo, sobre una imagen que tal vez pueda resultar extraña (aunque

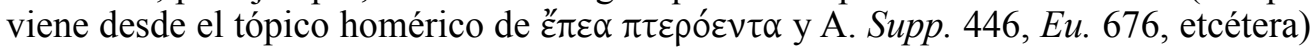

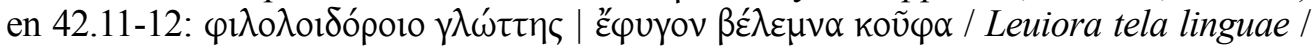
Fugio timens procacis (A: 38) / «De las saetas sutiles | (por ser formadas del soplo | que compone las palabras | en la boca del curioso) $\mid$ huyo, porque mi quietud $\mid$ no halle en su nota estorbo» (XLII, 35-40).

También amplifica, de diversos modos, desde el texto original y/o la versión siguiendo una asociación extensiva del mismo campo semántico. A veces, a través de

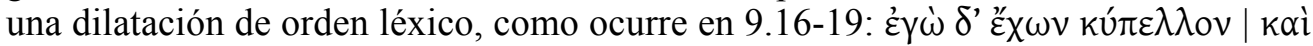

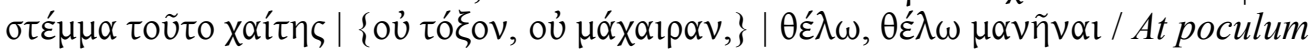
ipse gestans $\mid$ Et has comis corollas, | Non spiculum, nec ensem, | Furere hunc volo furorem (E: 101, 161); que Quevedo convierte en: «Yo, pues, que ni rodela | tengo, ni ronca trompa me desvela, | y mi armería, en vez de aljaba y cotas, | es bodega con jarros, tazas, botas, | armas que nada ofenden ni maltratan, | y a nadie, fuera de la sed, me matan, | bien, con mi bota sola | abrazado sin miedo, | enfurecerme honestamente puedo, | sin peto, ni espaldar, celada y gola» (XXXI, 27-36). El escueto paralelismo contrastivo entre ambos ámbitos de significado, las armas / el utensilio y adorno simposíaco, da lugar a una acumulación «actualizadora» de elementos afines. ${ }^{44}$ Por

${ }^{42}$ En Villegas (1941: 181): «El capadillo Atis» $(14,1)$.

${ }^{43}$ Las obras de Lipsius figuran en el índice de la Biblioteca de San Martín (Pérez Cuenca, 2003: 317), y fueron por supuesto manejadas por Quevedo.

${ }^{44}$ Ensanches similares pueden mirarse en Ronsard, véase O'Brien (1995: 167-168). De modo semejante, también actualiza por ejemplo en 11.13 / IX, 14: $\delta \rho \alpha \chi \mu \tilde{n} \varsigma$ / Drachma (A: 14) / «por un escudo»; 23.15 / XX, 21: $\sigma \alpha ́ v \delta \alpha \lambda o v /$ «chapín». Otro tipo de «modernizaciones» que practicó Ronsard (Giges / el «gran Turco») no se hacen presentes en el Anacreón, pero sí por ejemplo en las versiones sobre Marcial: Versiculos in me narratur scribere Cinna. | Non scribit, cuius carmina nemo legit (3.9, In Cinam); que Quevedo (1985: 451) transformó en: «Dice don Luis que me ha escrito | un soneto, y digo yo | que, si 
otra parte, la interpretación del sentido de una palabra permite un ensanche del texto y, de modo conexo, encauza el desarrollo del nuevo poema. Así para 10.1 / XII, 5-8:

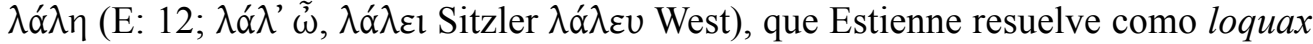
y que da lugar a cuatro versos quevedianos: «pues que con voz tan sin arte | porfías de esa manera. | Cantado siempre en mis salas, | y sabiendo que me ofendes». De modo palpable, Quevedo interpreta dicho término como «clave» de la queja de la voz lírica; sobre ello basa su amplificación, al tiempo que cubre con los dos primeros versos griegos los cuatro de la primera redondilla y así en la siguiente, distribuyendo en los ocho versos de ambas estrofas de forma simétrica los cuatro correspondientes del original.

c) Mediación de otros textos y tópicos. Varias son las amplificaciones por extensión contextual a partir de otras noticias eruditas. Así en el caso de 31.6 / VII, 23-26 ( traducciones: Propere perambulantem | Pupugit latenter hydrus (E: -, 123) / Miserum at momordit hydrus (A: 11); «cuando, vestida de yerbas, | disimulada entre matas, | mis plantas tocó una sierpe, | y el veneno mis entrañas». Parece probable que Estienne haya realizado su versión con un leve matiz virgiliano, latet anguis in herba (Ecl. 3.93; Georg. 4.457-459), y que Quevedo haya captado la alusión y la use y amplifique en su poema; pero es evidente que dicha lectura ha condicionado la resolución adoptada por éste («Ya del corazón mi vida / la ponzoña desataba»). ${ }^{46}$ Pues, en efecto, las versiones latinas de varias formas sirven como punto de partida a las propias extensiones que-

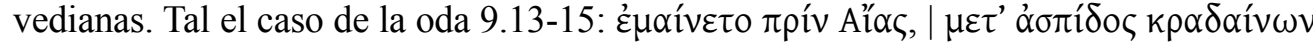
| toris coruscans, | Septemplicemque parmam (E: 101, 161); es decir, «completando» la escena del héroe enloquecido con famosas referencias homéricas sobre el escudo

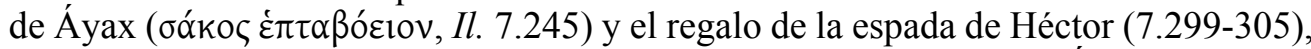
$\xi i ́ \varphi$ os ả $\rho \gamma v \rho o ́ n \lambda o v$. De ahí el correspondiente quevediano: «También Áyax, el rayo de la guerra, | furioso y enojado, | el escudo embrazado | de siete orbes finísimos armado, | esgrimiendo arrogante | la espada ardiente de Héctor fulminante» (XXXI, 21-26). ${ }^{47}$ Bien puede colegirse que Quevedo comprendía que tales elementos eran añadidos y

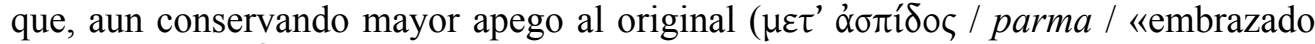

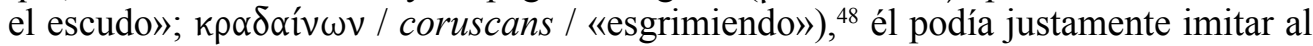

don Luis lo escribió, | será un soneto maldito. | A las obras lo remito: | luego el poema se vea; | más nadie que escriba crea, | mientras más no se cultive, | porque no escribe el que escribe | versos que no hay quien los lea». Quevedo se vale de Marcial y lo adapta a su situación contemporánea y personal, en su «guerra literaria» con Góngora; los versos del latino sirven para construir un texto que adquiere funcionalidad significativa particular para el poeta y los lectores del siglo XVII, y que muestra de nuevo la libre manera en que los clásicos grecolatinos son «puestos al día» por sus imitadores renacentistas y barrocos.

${ }^{45}$ Corr. de Salmasius a $\pi \varepsilon i \tilde{\rho} \varepsilon v$ del manuscrito.

${ }^{46}$ Como pasaje contrastivo en su nota para el final del poema, Quevedo recuerda a Prop. 3.13.11-18.

${ }^{47}$ Verter a través de la traducción de Estienne seguía ocurriendo en el siglo XVIII. Valga citar a este propósito el pasaje de la misma oda en la versión de Fawles (1760: 81): «Mad Ajax, with his sevenfold Shield, | Tremendous stalk'd along the Field, | Great Hector's flaming Sword he drew, | And Hosts of Greeks in Fancy flew».

${ }^{48}$ Destacado por Pérez Jiménez (2011: 121). 
helenista francés no sólo transladando dichas «aportaciones», sino, por supuesto, añadiendo las suyas propias cuando le pareciere pertinente.

Y así lo hace, en detalles o vastas adiciones. Una pincelada muestra el ya citado 24.5 /

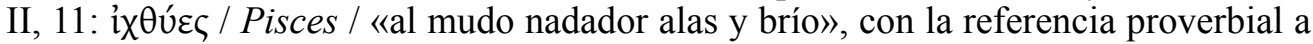

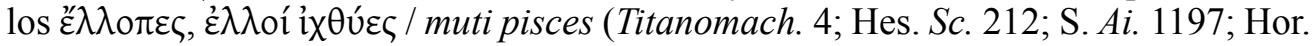
Carm. 4.3.19; Luc. Gall. 1, etcétera). Por su parte, en el verso tercero de la número 8 /

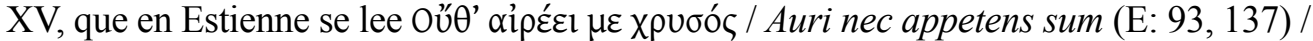
Amore tangor auri (A: 17) / «no busco el oro escondido» (5). En este caso, el adjetivo suplementario completa el verso y puede parecer fácil, pero es razonable suponer que Quevedo empleó el adjetivo «escondido» con base en el relato sobre Giges, con

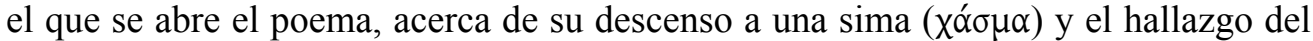

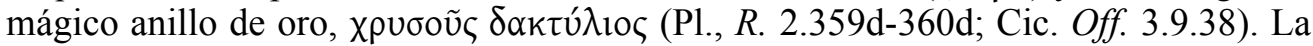
amplificación puede basarse en efecto en un referente culto que se añade a una escueta

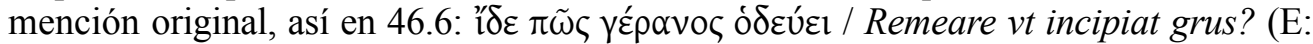
103, 169) / Redeant grues peregre (A: 34); que se transforma en XXXVII, 11-14: «mira las grullas, que con leyes viven, | cómo, volando, en letra el aire escriben, | y alegres vuelven por el aire vano, | como a ganar albricias del verano». La «escritura de las grullas $\rangle^{49}$ (además de sus migraciones regulares) ${ }^{50}$ aparece en algún poema quevediano. ${ }^{51}$ Otro añadido que sintetiza noticias mitológicas y «científicas» ocurre respecto de la abeja de Anacreon. 35 / XL, 7-10: «Madrugó para hurtar| lo que la mañana borda, | haciendo sus materiales | de los llantos de la Aurora»; es decir, el tópico de las lágrimas de la Aurora ${ }^{52}$ que forman el «rocío» y éste como el supuesto material usado por las abejas para producir la miel. ${ }^{53}$ Así, se ensancha por la sola asociación temática, como en el Fragmento II (Anacr. PMG 395), sobre el descenso al Hades se añade: «adonde delgadas sombras | sufren pena y gozan premio» (23-24); con el nítido uso

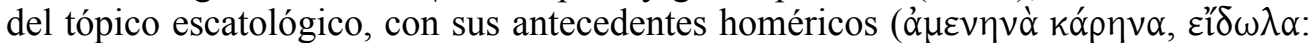
Od. 10.521, 11.83), de las tenues (Verg. Georg. 4.472) o leves umbrae ([Tib.] 3.7.6768 [Paneg. in Mess.]; Ov. Fast. 5.434; Sen. Oed. 562-563; V. Fl. 1.783).

Otro aumento o matización por vía de un texto intermedio muestra la oda 29A.6-8 /

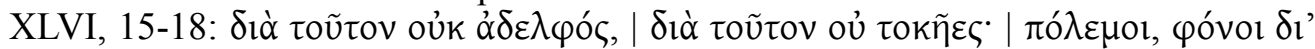

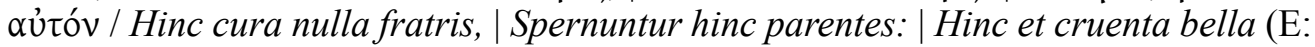
107, 183 y 185) / Iubet abnegare fratres | Pretium, iubet parentes. | Ciet et cruenta bella (A: 42) / «Por él entre los hermanos | amistades no se guardan, | ni se respetan los padres; | por él las guerras se trazan». Para su versión, según declara en la nota, ha tenido en cuenta unos versos de «Focílides», pertinentemente relacionados con este

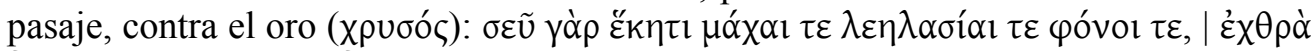

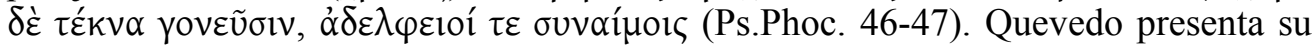

${ }^{49}$ Turbabis versus nec littera tota volabit, | Unam perdideris si Palamedis avem (Mart. 13.75.1-2). Véase Luc. 5.710-716; Philostr. Her. 709-710; Aus. Tech. 13.13; Claud. Bell. Gild. 474-478.

${ }^{50}$ Hom. Il. 3.3-5; Cic. N. D. 2.125.

${ }^{51}$ Quevedo: «vuela la grulla en letra, y con las alas | escribe el viento» (num. 466, 2-3).

${ }^{52}$ Ov. Met. 13.621-622.

${ }_{53}$ Arist. HA 5.22, 553b29-31; Plin. Nat. 11.12.30. Pudo sugerirle la interpolación la referencia al sustento de la cigarra de Anacreon. 34.1-3 / XLIII, 3-4, tópico muy común: Hes. Sc. 393-395, Theoc. 4.16, Verg. Ecl. 5.77, etcétera. 
versión en la nota: «Por ti el mundo | padece guerras, riñas, robos, muertes; | por ti, viendo que el hijo ha de heredarle, | es el hijo a su padre aborrecible; | por ti no tienen paz deudos, ni hermanos» $(37-41) .{ }^{54}$

También las amplificaciones por mediación de otros textos obedecen a distintos motivos y estrategias poético-interpretativas. Singular es el caso del último pasaje de

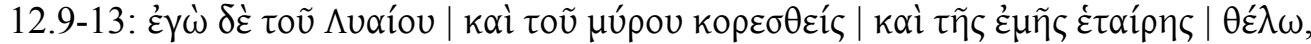
$\theta \varepsilon \dot{\lambda} \omega \omega \alpha \vee \tilde{\eta} v \alpha 1$. / Ego simul Lyaei, | Nardi simul fragrantis | Satur, simul puellae, | Libens libens proteruo | Praeceps agor furore (A: 16); se convierte en XIII, 11-18: "Yo sólo de tres maneras | soy furioso y arrojado; | pues la demasía del vino | vence mi razón a ratos; | también cuando harto estoy | de la fragancia del nardo, | y por hermosas doncellas | de juicio mil veces salgo». Pero el poema no termina ahí, sino que Quevedo le da un final extendido: «Así que de tres maneras | contino furioso ando, | ya bebedor, ya poeta, | y ya ciego enamorado» (19-22). La explicación está en la subsiguiente nota, pues lo que ha hecho Quevedo es relacionar el poema con una anacreóntica de Julius Caesar Scaligerus, que entiende basada en este texto: Si furor est Cupido, I Si furor est Lyaeus, | Si furor est Thalia, | Quoties furor, furor, furor | Amans, bibens, poeta? ${ }^{55}$ Quevedo sólo cita su versión en la nota («a la letra» según afirma, lo que pone de nuevo a la vista sus amplias licencias poéticas): "Siendo furor el amar | la voluntad y el querer, | si es furor también beber, | si es también furor cantar, | tres veces tengo furor, | furor, furor inconstante, | por poeta y por amante, | y por ser gran bebedor» (XIII, 26-33). De manera peculiar, Quevedo ha integrado a la oda griega el poema de Scaligerus, entendido como imitación de aquélla. La asociación no es del todo arbitraria, sobre todo teniendo en cuenta que el «furor poético» también es aludido en el poema griego (12.5-8) y luego fantasiosamente aplicado al uúpov del verso décimo. A la vista está que interesó a Quevedo destacar la clasificación de los furores, que deriva de las célebres enseñanzas platónicas sobre la divina $\mu \alpha v i ́ \alpha$ (Phdr. 244a-245c); adaptada aquí a una modalidad triple, báquica, erótica y poética, para colocar esta última en relieve en tanto que «furor divino» (70).

d) Modificaciones moralizantes. Como muestra el esbozo biográfico sobre Anacreonte que figura al inicio de la colección, la labor de traducir a un poeta «deshonesto» le resultaba a Quevedo en alguna medida inconveniente y trató de apologizar sobre su figura respecto de sus facetas más censurables. Pero preocupaciones de índole similar dejaron también diversas huellas en sus versiones. Así, en el poema que vierte Anacreon. 36, sobre la insensatez de procurar riqueza, inútil contra la condición mortal del hombre (tema del gusto quevediano), se agrega «Púdrase quien quisiere consumirse, | y mátese de miedo de morirse» (XXIII, 21-22). Es posible

${ }^{54}$ Con variantes en Phocílides (108-113), Quevedo (1985: 563). Cabe notar sobre el verso anterior,

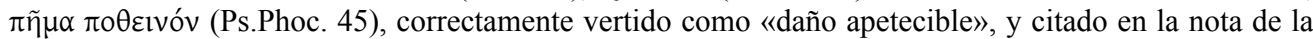
oda XXIII como appetecibile damnum. Tal vez Quevedo no calca alguna versión ajena, aunque es probable que la tenga presente (e.g. malum desiderabile en la de Sylburgius [1597: 101]). Pero también en el Phocilides se confirman sus prácticas como traductor, muy amigo de las amplificaciones (entre Ps.Phoc. 47-48, añade en su texto catorce versos más [114-127] sobre los pernicioso efectos del oro).

${ }^{55}$ En sus Anacreontica dedicados a Ronsard: Julius Caesar Scaligerus (1600: 476). El libro también - comprobando la utilidad de sus datos - en el índice de la Biblioteca de San Martín (Pérez Cuenca, 2003: 323). 
escuchar un eco de Marcial: Hic, rogo, non furor est, ne moriare, mori? (2.80.2), traducido por Quevedo («Matóse Testa al huir | de su enemigo el rigor. | Pregunto yo: ¿no es furor $\mid$ matarse por no morir?»). ${ }^{56}$ Esto confiere un matiz contrario al espíritu relajado y festivo del poema griego; dicha intrusión constituye una pincelada del moralista que aplica el texto de Marcial para dar un tono de acrimonia en la censura contra el deseo de oro («bien aparente» de la fortuna), como una suerte de «suicidio» vital y moral, opuesto a la razón y a la (cuando menos en este contexto) en menor grado reprensible actitud hedonista del cantor simposíaco y su gozo de «bienes naturales». Para 9.19 / XXXI, 35: $\theta \dot{\imath} \lambda \omega, \theta \dot{\varepsilon} \lambda \omega \mu \alpha v \tilde{\eta} v \alpha \iota$ / «enfurecerme honestamente puedo», Quevedo desdibuja la eficaz reiteración final del furor dionisíaco en favor de un «honestior furor» (el del hedonismo báquico frente a la posibilidad criminal de las armas).

Hay otras modificaciones moralizantes, como el fin de 39.5 / XLVII, 14: $\tau \dot{\alpha} \zeta \zeta \grave{\varepsilon}$

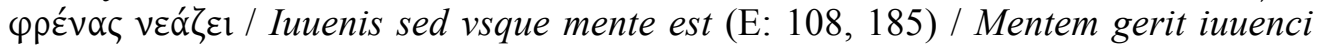

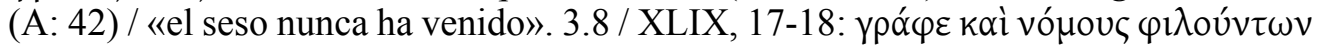
/ Etiam suas amantum | Mihi pinge sanctiones (A: 43) / «dibuja de los amantes | la determinación ciega». O bien, para la oda 30 / XLIV, Quevedo interpola dos secuencias de versos sin base anterior, una para ahondar en la caracterización del yo lírico («que yo nunca reposo, | sin pensión en mis gustos, | si lo son los que gozo», 4-6) y otra como una crítica a la oniromántica («Pregunto yo, adivinos, | agoreros famosos, | a quien errores nuestros | dan crédito de doctos», 19-22). Asimismo, en 49 / XXVII se ofrece el final modificado: «luego torno | a mostrar que en mi celebro | (gracias al ardor de Baco) | hay más calor que no seso» (XXVII, 15-18). La nota digresiva que la acompaña va justamente encaminada a destacar a la embriaguez como defecto moral. Tal vez la inclusión en un «apéndice» del Fragmento II (Anacr. PMG 395), haya sido incentivada también por motivaciones ético-religiosas, pues dicho texto servía para ilustrar «que Anacreón creyó la inmortalidad del alma, y en segunda vida, pena u gloria» $(31-32) .{ }^{57}$

Otra variante de traducción interpretativa vemos en la oda 52.1-4: Tí $\mu \varepsilon$ toù

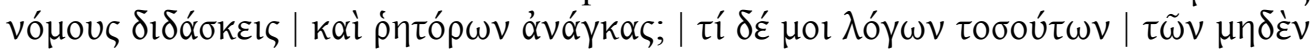
$\omega \emptyset \varphi \varepsilon \lambda u^{\prime} \tau \tau \omega v ; /$ Quid rhetorum doces me | Scita et necessitates? | Orationibus quid | Opus mihi tot istis, | Quibus nihil iunamur? (A: 33); que Quevedo convierte en: «¿Que me estás enseñando | filosofías vanas, | y de los sabios necios | sentencias y elegancias? ¿ ¿De qué puede servirme | la lógica más alta, | si sé por experiencia | que no aprovecha nada?» (XXXVI, 3-10). El poeta ha querido leerlo con asociación libre referido a la rhetorica philosophorum, y pareciere haber aplicado a su provecho

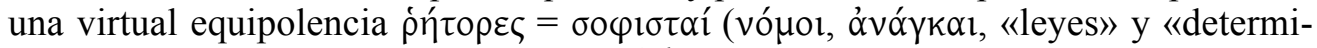
naciones lógicas») para luego convertir $\lambda$ óyol en «discursos racionales» («lógica»). Pues en su nota Quevedo muestra su interés por vincular contrastivamente el pasaje

56 Traducciones de Marcial, [42], Quevedo (1985: 467); y Nombre, origen, intento, recomendación $y$ descendencia de la doctrina estoica, Quevedo (1958: 974).

${ }^{57}$ El fragmento I en el Anacreón castellano corresponde a Anacreon. 41, y antecede al mencionado II (E: 55, 208-209, donde figuran en tercer y cuarto sitio) entre los varios textos incluidos por Estienne como supplementum a la colección. 
con la vana inquietud del letrado sobre la posteridad de sus obras (supuestamente en Boecio) $^{58}$ y la temática bíblica sobre la vanitas sapientiae (Eccl. II, 16), señalando que el poema griego hubiera estado «honestamente dispuesto» si como el principio fuera el fin, encaminándose a la virtud bien aleccionada por la «vanidad de vanidades» (Eccl. XII, 1 y 7-8). Su versión da lugar a tales consideraciones, aunque casi pareciere que Quevedo ha manipulado el texto de la anacreóntica con el fin de introducir esa reflexión edificante. ${ }^{59}$

e) Impulsiones lírico-estilísticas. Las alteraciones posibles de una traducción son múltiples. Algunas obedecen a la propia dinámica del nuevo texto, más tratándose de versiones en verso, donde no es raro que se agreguen o modifiquen palabras y aun versos en la forma secuenciada de la rima (por ejemplo, en XI, 5 y 19: «veras corvo tu cuello» $\mathrm{y}$ «de vino»); o bien, de manera más vasta, en razón de las estructuras métricas

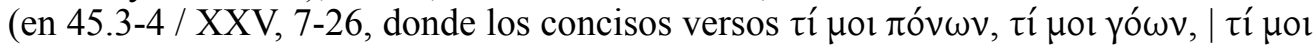

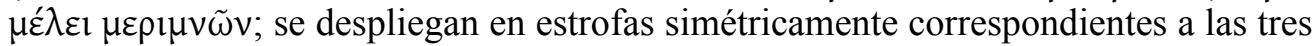
preguntas citadas). De cierto, en las muy libres versiones del Anacreón hay cambios y ampliaciones que parecen no obedecer a otra razón que el impulso lírico del poeta. En ellos suelen aparecer evidentes estilemas quevedianos, que se imponen por sobre el original griego y su mediación latina. Por ejemplo 37.11-12 / VIII, 15-16: દ̇ं

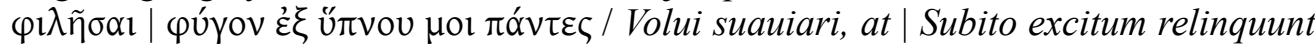
(A: 12) / «Quise besar las Ninfas, y al momento | dio libertad el sueño a mi cuidado».

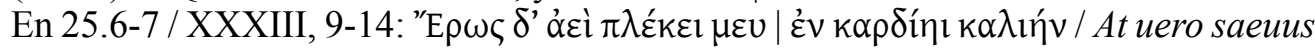
ille |Amor meo perennis | In corde nidulatur (A: 31), convertido en «no yo, que de Cupido | en verano y hibierno | soy un perpetuo nido, | soy un amante infierno, | pues en mi pecho anida | pollo que yo sustento de mi vida». Y en 38.24-25 / XLI, 55-60:

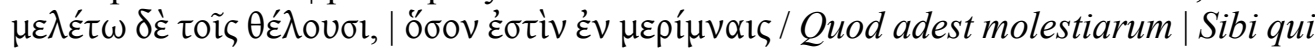
volent habento (A: 38) / «Y al que quisiere cuidados, | háganle muy buen provecho: que no le pueden faltar $\mid$ si es hombre y vive muriendo. |Y entretanto que él suspira $\mid$ debajo de tanto peso $[\ldots] \gg .^{60}$

No son escasos los pasajes que ilustran esta tendencia, en donde se despega del texto original resolviendo a su propia manera, como en el final de la oda 14.24-27 / XXXII, 31-34: «No son tantos los calores | que indios y garidas queman, | y bactrios, como los dulces | que alimento con las venas». Igualmente sin base alguna en el original o las versiones, como en 48 / XXVI: «en líquido fuego | arde el humor de mis venas; | luego que estoy del dios lleno» (5-7); o en 16 / XXVIII, 9-10, sobre la pintura: «donde segunda vez nacen | en doctas manos los muertos»; en este caso, es viable conjeturar que subyace una idea más o menos tópica sobre la pintura que jugaba incluso

${ }^{58}$ No en esos términos, pero Boecio sí trata en general el tema de la fortuna y la vanagloria, incluyendo la insignificancia del renombre frente a la eternidad (Philos. cons. II, 7 [Prosa], 9-19 y VII [Metro]; III, 6 [Prosa], 1-6).

${ }^{59}$ Por otro lado, la versión quevediana (XXXVIII, 31-34) cierra más abiertamente a la manera de

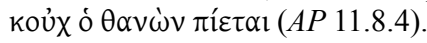

${ }^{60}$ A veces amplifica también con cierta sencillez sentenciosa; por ejemplo, en 8.9-10 / XV, 13-17:

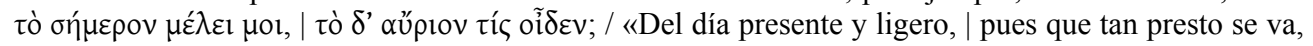
cuidar solamente quiero;| porque del día venidero | Dios sabe lo que será». 


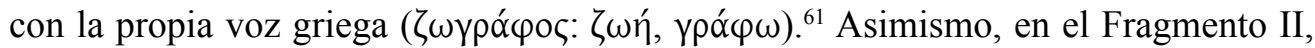
6-9 (Anacr. PMG 395.3), el poeta amplifica: «ya que se llevó tras sí | mi mocedad mis cabellos, | y que el llegar y el estar | y el irse fue en un momento».

También en la correspondiente a Anacreon. 59, donde la reiterada acción de beber le permite a Quevedo introducir una metáfora con pinceladas sombrías sobre el vino como sangre de Baco (Bassareus) mezclada con la sangre en la «prisión corpórea» del que bebe: «En bebiendo y alegrando | con sangre de Basareo | la mía triste, que yace | presa en las venas del cuerpo» (XXXIX, 27-30). Los rasgos negativos preparan el ensanche final, donde la sola mención de la muerte al término de la oda (59.28), toca una cuerda sensible de la lira quevediana que reverbera aumentándolo en doce versos más (39-50) con la alegoría de la «navegación de la vida» y el «puerto» de la «negra

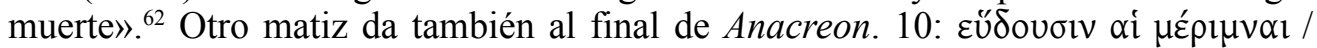
Aerumna dormit omnis (A: 24), que Quevedo convierte en «que es Lete el vino, en que beben / olvidos tristes memorias» (XXV, 37-38) ${ }^{63}$

De conformidad con lo visto, es pertinente remarcar el sentido estético de la dilatación quevediana del discurso, donde la amplificatio tiene el valor cualitativo de la $\alpha u ̋ \xi \eta \sigma r \zeta ~\left(A r i s t . ~ R h .1368 \mathrm{a} 10-33\right.$ ), que busca también «engrandecer» $\operatorname{los}$ textos. ${ }^{64} \mathrm{La}$ sublimada magnificación da lugar entonces a los precitados vuelos de pluma, algunos bastante singulares. Por ejemplo, con referencia a Anacreon. 40, donde tampoco hay antecedente textual para esta metáfora: «porque quiero alegrarme $\mid$ antes que, rigurosas, | del sudor de la muerte | me cubran negras olas» (XXIIII, 15-18). En una intrusión de lo más insólita, ajena también al tono general de la colección, Quevedo extiende su poema amplificando a su vez de modo original y ciertamente «barroco» la idea del «sudor de la muerte» ${ }^{65}$ que se convierte en los oleajes del «mar de la muerte» ${ }^{66}$ Es una muestra más sobre cómo, en desmedro de la fidelidad pero en beneficio de la poesía, Quevedo se deja llevar por el estro de su poderosa imaginación que a menudo desborda los modestos vasos de sus modelos.

f) Lecturas alegóricas. Hay cierta tendencia en el Anacreón a interpretar «alegóricamente» algunas designaciones. Por ejemplo, Dioniso (44.1-2 / V, 3-4), para el que los traductores latinos utilizan Lyaeus $(\mathrm{E}: 88,125)$ y Semeleius (A: 9), Quevedo vierte

${ }^{61}$ Tópico presente por ejemplo en Den Grondt der Edel vry Schilder-const (XII, 1) del pintor, tratadista de arte y traductor de Homero Karel van Mander (1604: 21r), sobre la «resurrección» que logra la pintura. Véase la silva de Quevedo «Al pincel» (núm. 205).

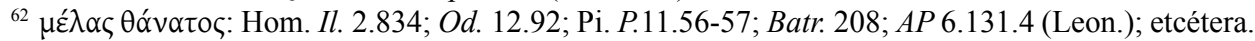

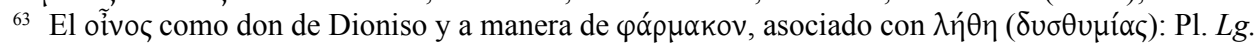

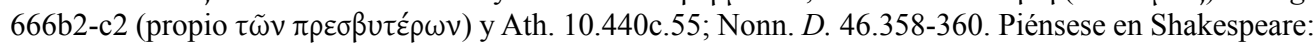
«Come, let's all take hands | Till that the conquering wine hath steeped our sense | In soft and delicate Lethe» (Antony and Cleopatra II, 7, 103-105).

${ }^{64}$ Aunque bajo los prejuicios de su época sobre el «mal gusto» barroco, Rubió y Lluch (1879: 117) anotaba no sin acierto sobre Quevedo y su versión anacreóntica: «Su genio poético se avenía mejor con los asuntos grandes y que exigían profundidad o alteza de pensamientos, que con los delicados y de menos subido tono».

${ }^{65}$ El sudor letalis, como en Virgilio: incertus ibidem | sudor et ille quidem morituris frigidus (Georg. 3.500-501); Servio ad loc. (Thilo III, 315): frigidus sudor mortis futurae signum est.

${ }^{66}$ «Nuestras vidas son los ríos | que van a dar en el mar | que es el morir» (Jorge Manrique, Coplas a la muerte de su padre, [III], 25-27). 
como «vino»: «Mezclemos con el vino diligentes | la rosa dedicada a los amores»; y en su nota explica que, por sugerencia de Francisco de Rioja, ve en el pasaje una alusión a la costumbre de adornar (o incluso mezclar) las copas de vino con flores (coronare

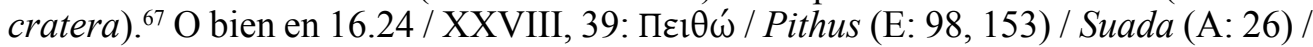
«La Persuasión»; de modo legítimo anota: «Por eso traduje yo, no la diosa con nombre latino, como Elías Andrea, ni con nombre griego, como Henrico Estéfano, sino lo que significa, que es lo que más hace al intento del poeta» (102-104). En otras expande el justificado énfasis de la traducción, como en 38.8 / XLI, 15: xópıৎ (E: 37) / Charis

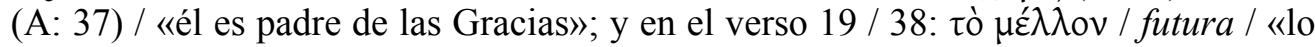
venidero» que da lugar a una interpolación sobre el Tiempo (41-46).

Ciertamente, diversos sesgos alegóricos pueden encontrarse en los propios textos originales, algunos palmarios (como en Anacreon. 30 o 31) y otros más plegados (18). ${ }^{68}$ Por ejemplo, en Anacreon. 4 (transmitida también por Gel. 19.9.6 y AP 11.48), la voz lírica pide a Hefesto la hechura de una copa, decorada no con motivos astronómicos (el Carro, Orión, las Pléyades, el Boyero) sino dionisíacos y eróticos. Es posible que su autor estableciese una relación no sólo con el pasaje del escudo de Aquiles (Il. 18.485-489), sino con el de la copa de Néstor (11.631-635), leída como una alegoría cosmológica (las «palomas», $\pi \varepsilon \lambda \varepsilon l a ́ \delta \varepsilon \varsigma$, como las «Pléyades», según Moiro) expuesta por Asclepíades de Mirlea (Ath. 11.489c-492d, 78-82); parece además que aplicó en ello la tópica relación del escudo y la copa como emblemas divinos (Arist. Po. 1457b20-22; Rh. 1407a15-18) para una jocosa inversión simposíaca de los motivos homéricos. Este poema ecfrástico se relaciona con el siguiente sobre similar asunto (5 / XVIII), tras el cual Quevedo incluye una larga nota digresiva para discutir el tema del tamaño de las copas antiguas y sobre cómo pudo embriagar Odiseo a Polifemo (con base y en disputa con Ath. 11.461a-e, 4), donde recuerda además la alegoresis de la copa de Néstor recuperada por Alciati (Scyphus Nestoris). ${ }^{69}$

Que elementos cosmológicos son propios de los poemas ecfrásticos es tenido

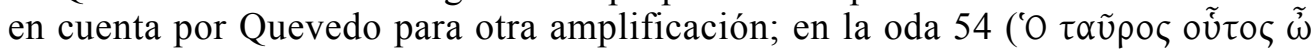
$\pi \alpha \tilde{\mathrm{l}})$, sobre el toro del rapto de Europa, donde interpola los versos: «el dios del alto coro, | que por cuernos pudiera | traer los de la luna, si quisiera; | y bien pudiera usar desta grandeza, | si gustara de honrarlos, | tan sólo con pasarlos | del pie, con que los pisa, a su cabeza» (XXXV, 4-10). El juego verbal y metafórico sobre «los cuernos de la luna» ${ }^{70} \mathrm{y}$ los del toro (lunata frons) puede apoyarse imaginariamente en el catasterismo de Tauro. ${ }^{71}$ En la écfrasis de la imagen marina de Afrodita (Ana-

${ }^{67}$ «Equivocando» Il. 1.470, en una modalidad repetida por los poetas latinos: Verg. Georg. 2.528: et socii cratera coronant, | te libans, Lenaee, uocat; Aen. 1.724: uina coronant; Aen. 3.525-6: tum pater Anchises magnum cratera corona $\mid$ induit impleuitque mero; Hor. Carm. 3.13.2: dulci digne mero non sine floribus; Tib. 2.5.98 : coronatus... calix; Serv. Aen. 1.724 [Thilo I, 201, 28]: antiqui coronabant pocula, et sic libabant.

${ }^{68}$ Donde Batilo es representado como un árbol e incluye el double entendre de una alegoría sexual indicada por West (1984: 210).

${ }^{69}$ Alciati (1546: 9v).

${ }^{70}$ Verg. Geor. 1.431-433; Aen. 3.645; Ov. Met. 2.116-117, 3.682; Luc. 1.217-218; etcétera.

${ }^{71}$ Eratosth. Cat. 14; Ov. Fast. 5.603-606; Man. 2.489-491; Germ. Arat. 536-539; Hyg. Astr. 2.21; Nonn. D. 1.355-362. Recuérdese el «media luna las armas de su frente» (Soledad I, 3) de Góngora, lector también del Anacreón. 
creon. 57), añade detalles tomados de diversas fuentes, como «sienten los peces su fuego» (LI, 57), sobre el dominio universal del amor y su «llama» que incluye a los peces y divinidades marinas (Verg. Georg. 3.242-244; Sen. Phaed. 330-337; Orph. H. 58.4-7), es decir, «los dioses verdes se abrasan» (LI, $58=$ uirides dei: Ov. $\operatorname{Tr} .1 .59)$.

Quevedo también participaba en alguna medida de las lecturas alegóricas sobre los poemas homéricos. Al menos así lo sugiere un comentario al paso en contra de Scaligerus y la promesa sobre una obra no realizada: «como yo probaré en la defensa de Homero contra las calumnias de Julio Escalígero, y otros desta seta, apóstatas de la buena fama del padre de todas las sciencias» (I, 144-146). ${ }^{72}$ Esto insinúa un texto en la modalidad de aquellas antiguas apologías sobre el poeta, que lo presentaban en efecto como «padre» de todo saber, al modo de las Quaestiones Homericae de Heráclito el alegorista o el De Homero del Pseudo-Plutarco. No se le puede censurar a Quevedo esta tendencia, si la siguieron autores como Poliziano (quien se apropió del De Homero para su Oratio in expositione Homeri) o incluso Jean Dorat. En cualquier caso, su preocupación por defender en todo al padre de la poesía es manifiesta en el viraje que hizo sobre Anacreon. 2.1-2 / XLVIII, 3-10:

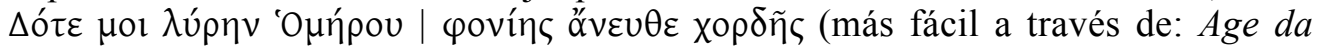
lyram mi Homeri, | Vbi chorda abest cruenta, A: 42): «Dadme la lira de Homero, | adonde nunca la guerra | manchó con sangre u con llanto | las más que divinas cuerdas. | Dadme la lira süave, | en quien su garganta diestra | fue admiración de los dioses $\mid$ y pasmo de las estrellas». ${ }^{73}$

${ }^{72}$ El asunto lo trató Quevedo en su correspondencia con Lipsio (Cartas 95 y 97), fervoroso admirador de Homero, que lo animó a dicha tarea: o fac, non potes dignius, et sapientibus gratius, argumentum tractare (Ramírez, 1966: 400-401 y 412). Bien conocida es la inquina de Julius Caesar Scaligerus (1561: 214 ss.) contra Homero, incluyendo las apologías alegóricas, y su exaltación del poeta noster, Virgilio. Quevedo (1999: 247-248) lo presenta entre los condenados en el Sueño del infierno, por sus «desvergonzadas mentiras» contra Homero y ser «idólatra de Marón». También dice en La cuna y la sepultura (IV): «A Homero llaman Platón y Aristóteles padre de la sabiduría y fuente de la dotrina; y Escalígero y otros muchos le llaman caduco y borracho: y a ellos los tratan otros peor» (Quevedo, 1958: 1208b).

${ }^{73}$ Sobre las citas homéricas incluidas en la nota de XLIII, véase lo apuntado por Moya del Baño (2006b: 375-376 y 377, n. 117). Dados los numerosos empréstitos de las versiones latinas de Homero en el Renacimiento, no es tan fácil determinar de modo exacto qué texto en cada caso sigue Quevedo (donde además parece introducir algunas pequeñas modificaciones); aunque resulta más probable que haya usado no directamente las versiones de Spondanus o la de Hessus (indicadas por Moya del Baño), sino la de Estienne (1589), basada a su vez en las versiones antecedentes. En los pasajes en cuestión, para Il.3.149-153, la de Spondanus es idéntica a la de Estienne, que deriva de la publicada por Crispinus en 1570 y revisada por Franciscus Portus en 1580 (véase Sowerby, 1996). Sin embargo, para Il. 5.339-342, la de Estienne es más semejante a la citada por Quevedo: fluebat autem immortalis sanguis deae, | (Cruor, qualis fluit nempe beatis diis. | Non enim frumentum edunt, neque bibunt ardens vinum: | Ideo exangues sunt, et immortales appellantur). Véase Estienne (1604: 115-117 y 193). 


\section{INFLUJO DE LAS ANACREÓNTICAS EN LA POESÍA QUEVEDIANA: UN EJEMPLO}

Varios son los paralelos posibles que evidencian cómo el Anacreón sirvió también de surtidor para la «poesía original» de Quevedo. ${ }^{74}$ Vale la pena detenerse en un

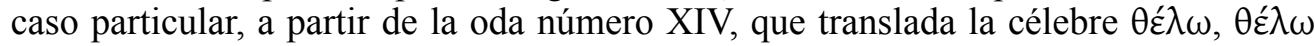
$\varphi \imath \lambda \tilde{\eta} \sigma \alpha$ l. En el poema, el yo lírico, que se ha negado a ceder a las demandas de Eros, se enfrenta contra el enfurecido dios, que lanza sus flechas infructuosamente. Ante esto,

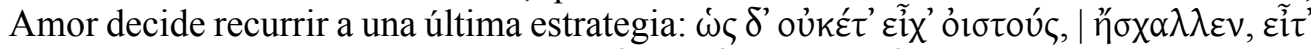

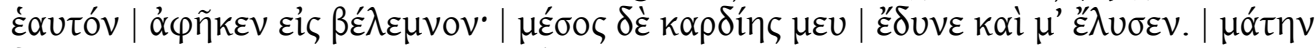

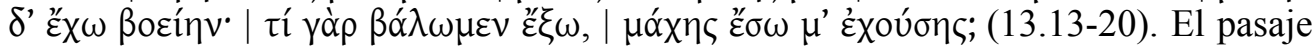
ha sido tan del gusto del poeta que se ha deleitado en una considerable amplificación: «De tal manera tiró, | que le faltaron las flechas; | y así, enojado y corrido, | para burlar mi defensa, | él mismo se tiró a mí | en lugar de una saeta, | y desatando mis miembros, | abrió en el corazón puerta. | Aposentóse en mi alma, | y siendo huésped en ella, | en maltratar su hospedaje | muestra toda su grandeza. | Que Amor batalla invisible, | en lo más guardado entra, | en lo más secreto habita, | en lo más hondo se cierra. | Y así, las armas y escudo | ninguna cosa aprovechan, | ni estando el contrario dentro | hacer la guerra acá fuera» (XIIII, 23-42). Se trata, en efecto, de una de las Anacreónticas más agudas en su conclusión. Amor se vuelve a sí mismo en venablo, se instala en el pecho del elusivo combatiente y hace ahí su morada, desde la cual tortura su huésped y para cuyo ataque no hay ya defensa posible.

El tópico del amor que ejerce su influjo desde el interior de quien ama con efectos físicos y psíquicos diversos es antiguo $;{ }^{75}$ se pudo vincular con el de las saetas del dios que, identificadas con los propios «dardos» de la mirada ${ }^{76}$ se convierten en medio y camino suyo hacia el corazón. ${ }^{77} \mathrm{El}$ motivo del Amor que mora en el interior del hombre se hace presente en al menos dos conocidos sonetos quevedianos. Así, en «No me aflige morir; no he rehusado...» (núm. 479), se halla el verso «donde todo el amor

${ }^{74}$ Por ejemplo, en la poesía satírica, donde, según ha señalado Cacho Casal (2003: 48), el último verso del soneto «Mejor me sabe en un cantón la sopa» (núm. 519, 14: «él asido a Fortuna, yo a la cepa») puede relacionarse con el final de Anacreón XXIIII (la temática central del desprecio de la riqueza, «Llenar, no enriquecer, quiero la tripa», desarrolla el contraste de la oda anterior, la XXIII). Por su parte, en la poesía amorosa, desde 44.1-4 / V, 3-7: «Mezclemos con el vino diligentes | la rosa dedicada a los amores $\mid$ y abrazando las frentes | con las hermosas hojas y colores | de la rosa, juguemos descuidados»; que aparece reelaborado en: «Coronemos con flores | el cuello, antes que llegue el negro día. | Mezclemos los amores | con la ambrosia mortal que la vid cría» (núm. 384, 61-64). O bien, Quevedo de modo directo se «copia a sí mismo» desde algunos de sus propios añadidos en el Anacreón: 7 / XI, 10: «la boca, de los años saqueada» (= núm. 1, 6; anotado por Rey, 1999: 177); o 16 / XXVIII, 9-10, sobre la pintura: «donde segunda vez nacen | en doctas manos los muertos» / «en docta mano | mentir almas los lienzos de Ticiano. Entre sus dedos vimos $\mid$ nacer segunda vez [...]» (núm. 205, 68-71); etcétera.

${ }^{75}$ Hes. Th. 120-122; Alc. PMG 59; Sapph. Voigt 47.130. O que literalmente «se precipita» en el que ama: in me tota ruens Venus (Hor. Carm. 1.19.9).

${ }^{76}$ A. Supp. 1003-1005, A. 742-743. Quevedo añade en 59 / LII, 58: «los dos ojos, de Amor flechas», tópico muy extendido en la poesía renacentista.

${ }^{77}$ Prop. 2.12.5-6, 13-16; Ach.Tat. 1.4.4.1-4; Apul. Met. 10.3.21-23; Hld. 3.6.5.2-8; Eust. Macremb. 3.1.6. 
reinó hospedado» (8). ${ }^{78}$ Pero, por supuesto, el verso más célebre corresponde al primer terceto de «Amor constante más allá de la muerte» (núm. 472): «Alma a quien todo un dios prisión ha sido». Su exégesis no está exenta de un básico disenso. Han figurado dos interpretaciones: una lee que el dios sirve de cárcel al alma, y otra entiende que el alma ha sido prisión para el Amor. María Rosa Lida (1939: 374, n. 1) fue quien propuso que el verso debía leerse "Alma, que a todo un dios prisión ha sido...», respetando «el riguroso esquematismo de los tercetos» y con la evidente pertinencia semántica de «encarecer la magnitud vital» del alma. ${ }^{79}$ Según apunta Jauralde Pou (1997: 98), Amado Alonso, Lázaro Carreter y — parcialmente - Carlos Blanco Aguinaga secundaron esta lectura alternativa. ${ }^{80}$ Atendiendo al ejemplo de Anacreon. 13, podría clarificarse la enmienda de Lida y fundarse sobre una fuente indisputablemente conocida y asimilada por el poeta. En efecto, la imagen del dios albergado en el pecho del amante tiene su correspondiente en la oda griega, que en la versión quevediana dice: «Aposentóse en mi alma...». Así, recurrir a la oda para iluminar el soneto redunda en claras ventajas interpretativas: respeta la simetría de las cláusulas; evita la disonancia conceptual e imaginaria de un alma contenida (y «liberada» con la muerte) para volverla en constante continente del Amor, de conformidad con los procesos físicos (y «metafísicos») de los versos subsiguientes; y evitando el extraño supuesto de que el propio dios sea la cárcel del alma (y no el carcelero de su prisión, como ocurre en el tópico alegórico medieval), facilita comprender que se trate en efecto de «todo un dios», el Amor que íntegramente la habita («donde todo el amor reinó hospedado»), tal y como sucede en el modelo anacreóntico, ${ }^{81}$ convertido esta vez en "prisionero» ${ }^{82}$ que obra desde dentro una alquimia transfigurativa cuyas cualidades son ya plenamente asimiladas como propiedad del alma en la transcendencia. ${ }^{83}$

${ }^{78}$ Hay otras elaboraciones de la imagen, como: «En mi pecho, el Amor, que me lastima, | lee de dolor la cátedra de prima» (núm. 387, 5-6).

${ }^{79}$ Dicha propuesta ha sido objetada por otros críticos. Por ejemplo, Olivares (1995: 165-166) llamó la atención sobre los versos tercero y cuarto, sobre la «liberación» del alma («subyugada por el Amor») del cuerpo, para contravenir tal lectura; pero no corresponde al sentido final del verso noveno y del término del soneto, que tiene como fin justamente lo opuesto, no la «disolución» negativa sino la permanencia del amor («su cuidado») como algo «constantemente» poseído por ella y que transciende al cuerpo (dejando perennes huellas, que lo justifican, en sus propios despojos) y la muerte misma.

${ }^{80}$ Roig Miranda (2007: 514) observa: «Las dos lecturas tienen sentido y proporcionan una concepción diferente del amor». Por cierto, Quevedo puede tensar de modo inextricable la paradoja de un amor sin escapatoria tanto interior como exteriormente: «yo estoy todo en Inarda, y toda ella | está en mi corazón, dándome guerra: | y cierro, amante, a quien en sí me cierra» (núm. 387, 82-84).

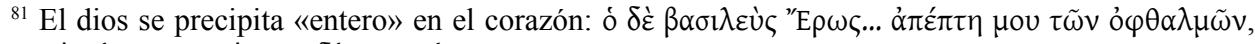

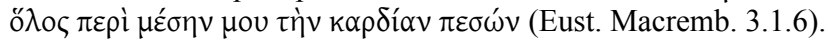

${ }^{82}$ En otro soneto dice la voz lírica, burlándose de Amor: «Esclavo eres de Lisi en prisión dura, | ¿y que te sirva yo de esclavo quieres?» (núm. 468, 3-4). En este caso, como destaca Fernández Mosquera (1999: 61), «la transformación quevediana estriba en convertir a Amor en prisionero de Lisi». En el soneto mayor, radicaría en transformar a Amor en prisionero del alma, que desde una posición de dominio se arroga la posesión constante y transcendente de él.

${ }^{83}$ Cabe, por otra parte, la posibilidad de que Quevedo haya también aplicado a tal propósito célebres expresiones de los maestros latinos sobre la inmortalidad que confiere la poesía: non omnis moriar multaque pars mei | vitabit Libitinam (Hor. Carm. 3.30.6-7); ergo etiam cum me supremus adederit ignis, | vivam, parsque mei multa superstes erit (Ov. Am. 1.15.41-42). Valga mencionar además que las Musas son 
De tal suerte, resulta plausible suponer que Quevedo haya tenido en cuenta dicho pasaje anacreóntico al momento de escribir su célebre soneto. Cabe destacar que, en el comentario a la oda anterior (12 / XIII), cita un verso de Virgilio concurrente a este propósito: Ardet amans Dido, traxitque per ossa furorem (Aen. 4.101), y que traduce: «Arde la enamorada Dido, y corre | en llamas el furor por sus medulas». Es además probable la utilización de un notorio texto de Propercio, donde en cierta medida se resumen ideas semejantes al texto griego (pues involucra presencia y acción interiores del Amor) y el virgiliano: in me tela manent, manet et puerilis imago: | sed certe pennas perdidit ille suas; | evolat heu nostro quoniam de pectore nusquam, | assiduusque meo sanguine bella gerit. | quid tibi iucundumst siccis habitare medullis? (2.12.1317). ${ }^{84}$ Sobre tales antecedentes debe inspirarse el terceto aludido: «Alma, a quien»/ «Alma, que a todo un dios prisión ha sido, | venas que humor a tanto fuego han dado, | medulas que han gloriosamente ardido». Por todo ello, cabe decir que, conjuntamente leídos, la anacreóntica y los pasajes de los poetas latinos hacen más practicable la lúcida emendatio de Lida y leer así, no conforme con el tópico de la «cárcel de amor», sino a partir de esa otra forma más compleja e inexorable que se reescribe en una modalidad transfigurada, donde la «prisión», en la dinámica físico-psicológica descrita en el soneto, tiene una definida dimensión interior (propia al imaginario cristiano: carcer cordis; Prud. Psych. 906) y, en este caso, transcendente y triunfal. De modo consecuente, un autor como Quevedo, embebido de tradición clásica, asimila numerosos tópicos de la literatura antigua, los cuales pueden aparecer, trasformados por su particular genio, en algunas de sus más personales creaciones.

\section{CONCLUSIONES}

Según lo visto, es legítimo afirmar que las versiones quevedianas del griego suelen ser tributarias de traducciones latinas precedentes, tal y como ya mostrara BénichouRoubaud, quien, por otra parte, ha recargado de más sus tintas insistiendo en las falencias filológicas de Quevedo de una manera excesiva ${ }^{85} \mathrm{y}$ en ocasiones impertinente. Por el contrario, equilibrando la balanza crítica, Pérez Jiménez ha proporcionado ejemplos probatorios de que el poeta «conoce el griego y que tiene en cuenta habitualmente el texto griego» por lo que sí cabe considerarlo «un helenista». ${ }^{86} \mathrm{Si}$, a pesar de esto, el

capaces de hacer cautivo a Eros: Anacreon. 19 / XXX (relacionado con el poema núm. 468 por Schwartz, 2001: 1193-1194).

${ }^{84}$ Asimismo: isti enim tui oculi per meos oculos ad intima delapsi praecordia meis medullis acerrimum commouent incendium (Apul. Met. 10.3.21-23).

${ }^{85}$ También recriminó Bénichou-Roubaud (1960: 63) que empleara no los nombres propios griegos sino sus correspondientes latinos, muchas veces ya en las versiones intermedias; Pérez Jiménez (2011: 106) ha matizado esto mostrando que no calca siempre a Estienne o André. Además, se trata de una práctica muy extendida en el horizonte renacentista-barroco (y aun en siglos posteriores), que incluye la hispanización de los nombres en lenguas extranjeras, y cuya convención atiende a los propios conocimientos de los lectores. E incluir en la lista como «latinismo» lejano a la letra griega «Osa» por "А $к \tau о \varsigma$ (Ursa, E: 86, 115; Helix, A: 7) confirma los excesos de la precitada crítica.

${ }^{86}$ Pérez Jiménez (2011: 126). 
peso de la mediación latina es evidente, ello en múltiples casos resulta comprensible tanto por la dominancia humanista del latín como por su clara conveniencia lingüística respecto del español; pero también, en efecto, por la propia competencia del poeta, cuyas facultades como latinista fueron notoriamente superiores (bien lo muestra el escritor epistolar que sorprendió a Lipsio). ${ }^{87}$ Pues tampoco es plausible exagerar el helenismo de Quevedo. Ya Antonio López Eire (1982) ha mostrado que, en su Epicteto, dependió en buena medida de la versión castellana del Brocense (cuya predilección sobre la de Correas la ha advertido el propio autor en su «Razón de esta traducción», por juzgarla «docta y suave, y rigurosa en lo importante; no en lo impertinente», ${ }^{88}$ criterio que aplicaba en sus propios ejercicios). Existen además otros tantos testimonios que evidencian cómo el poeta a menudo se acercaba a los textos griegos a través de intermediarios latinos. Con todo, un análisis ponderado de esos mismos ejemplos autoriza la conclusión de que «su griego sabía» ${ }^{89}$ y que ese conocimiento fue cuando menos mediano ${ }^{90} \mathrm{o}$ aun «más que mediano $»^{91}$ y deja huella en distintos lugares de su obra. $^{92}$

Cabe asimismo estimar las características de las versiones quevedianas que, más allá del desenfoque histórico y la petulancia de un abordaje filológico taxativo, se revelan al análisis como textos fruto de sutiles operaciones literarias; su carácter poliédrico obedece también, en buena medida, a tendencias múltiples y contradictorias de su complejo autor, en el que, laborando bajo los paradigmas de su época, vemos converger y también disputar las figuras del clasicista amateur, el crítico literario, el humanista cristiano, el moralista y, por encima y triunfando sobre ellos, el creador verbal. Transcendiendo sus conjeturables errores y «afectaciones» críticas y sus licencias literarias, el Anacreón castellano vale por sus indisputables ejercicios de erudición ${ }^{93}$

${ }^{87} \mathrm{Y}$ el más amplio saber y aun los diversos aciertos que pueden encontrarse en sus consideraciones sobre textos latinos (así en la nota a Anacreón castellano XLVI, sobre Petr. 137.9.1); véase Moya del Baño (2006c). De manera inconsecuente, si se le presenta como copista de los traductores, BénichouRoubaud (1960: 55) subrayó errores latinos de Quevedo, que, en efecto, los comete, aunque parecen ser propios de descuidos y lecturas apresuradas (Schwartz, 2001: 1176-1177, n. 22); e.g. 38.7 / XLI, 13-14: Mé $\eta$ / Temulentia [A: 37] / «Él inventó los temblores | alegres, ya que no honestos», donde no cabe sino pensar que ha leído «Tremulentia» (véase Hoven 1994: 372).

${ }^{88}$ Quevedo (1985: 489).

${ }^{89}$ López Eire (1982: 243).

${ }^{90}$ Como opina Enriqueta de Andrés (1988: 185-186).

${ }^{91}$ Moya del Baño (2006a: 702, n. 21).

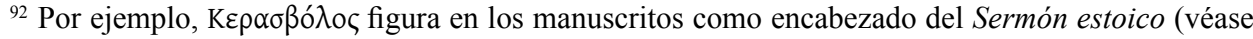
Quevedo, 1969: 293), con base en Teofrasto (CP 4.12.13) y Plutarco ( $Q u$. conv. 7.2.700d sobre Pl., $L g$. 9,853c-d). Sin duda manejó el comentario de Scaligerus (1566: 254C), que cita en la nota a la oda V del Anacreón (y que figura también en el índice de la Biblioteca de San Martín: Pérez Cuenca, 2003: 324), pero ciertamente conoció la aplicación moral platónica discutida por Plutarco. También cabe mencionar la pincelada señalada por López Grijera $(1998:$ 60-61, 124) en la anotación 68.2 en el ejemplar de la Rhetorica de Aristóteles perteneciente a Quevedo, con la adaptación castellana «julopézicas naves» de

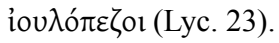

${ }^{93}$ Exaltados por Rubió y Lluch (1879: 117), respecto de sus comentarios: «En ellos pone de relieve su erudición portentosa, la rica fecundidad de su memoria, la variedad sorprendente de sus conocimientos, y en una palabra su talento universal. Creemos que cuantos se dediquen a estudios críticos o de erudición sobre las anacreónticas griegas, hallarán en los comentarios de Quevedo un minero abundante 
- y a veces por sus intuiciones y aun sus inconsecuencias geniales - y abona, como apuntaba Menéndez Pelayo (1953: 101), más a la honra que al desdoro de su autor. Es, de cierto, un referente necesario para trazar la historia de la recepción de los Anacreontea en lengua castellana, como su proteica pero notable puerta de acceso, junto con la próxima y más ajustada versión (sobre todo en el «tono») ${ }^{94}$ de las Eróticas de Villegas. Toda traducción es histórica y su función como tal es operativa en un ámbito temporal más o menos restringido; pero la que realiza un poeta mayor posee por sí misma un interés propio. Bien puede decirse que Quevedo, dominado por su genio creativo, en no escasas ocasiones ha rebasado los límites de la traducción literal y el trasunto fiel (interpretatio fida), desbordando incluso lo que cabe entender stricto sensu por una «paráfrasis $»{ }^{95} \mathrm{o}$ distendiéndola en una modalidad de interpretatio arbitraria que usa fuentes diversas a «juicio y arbitrio» del traductor y que da por resultado una «obra propia». ${ }^{96}$ En efecto, aunque el poema griego subsiste como substrato textual, el autor ofrece sobre él un «poema nuevo» (¿y no es ésta también una manera, más riesgosa pero a veces más fecunda, de «revivir» los textos?); pues es posible considerar sus odas, desde una óptica moderna, como «recreaciones» o «transcreaciones» (el «make it new» de Pound, o bien, para usar el juego de palabras de un discípulo quevediano en el siglo xx, Octavio Paz, «versiones y diversiones»). Por ello se levantan sobre la caducidad del texto intermediario, y constituyen con justeza una parte más de la obra poética de Quevedo. Perduran así a manera de una ramificación secundaria pero fructífera de sus vastas labores, como textos por sí mismos dignos de lectura y como otra vía de acceso para introducirse al taller literario del poeta doctus.

\section{BiBLIOGRAFÍA}

Alciati, A. (1546), Emblematum libellus, Venecia, Aldus.

André, É. (1556), Anacreontis Teii antiquissimi poëtae Lyrici Odae, ab Helia Andrea Latinae factae, París, Robertus Stephanus y Guilelmus Morelius.

\footnotetext{
y riqueza de datos bastante a satisfacer su curiosidad». Y aun Bénichou-Roubaud (1960: 72) le concedía sus «lecturas variadísimas» que «representan un trabajo considerable de compilación e investigación».

${ }^{94}$ Rubió y Lluch (1879: 114).

${ }^{95}$ Si como dirá Dryden (1961: 237) la paráfrasis es una «translation with latitude, where the author is kept in view by the translator, so as never to be lost, but his words are not so strictly followed as his sense; and that too is admitted to be amplified, but not altered». Sin duda en el Anacreón no se evitan diversas alteraciones del sentido; pero acaso el reparo mayor imputable a las versiones quevedianas radica no en el «significado», sino en el modo en que se alejan del tono y el «espíritu» de los originales, algo señalado como guía paradigmática por Luis Vives, «meterse en el espíritu» del autor, imitar a profundidad nec ossa solum sed etiam sanguinem (Lindeman, 1981: 211); mientras que Quevedo usa a veces los poemas como vasos para verter la sangre viva de sus propios conceptos.

${ }^{96}$ Según la explicación de Andreas Schottus (1610: 320) sobre el arbitrarius interpres: Arbitrarium vero Interpretem nomino, qui argumentum aliunde mutuatus, e fontibus illis suo iudicio arbitrioque, quantum, quoque modo videtur, haurire, et in suum opus deriuare satagit (4.10).
} 
Andrés Castellanos, E. de (1988), Helenistas españoles del siglo xVII, Madrid, Fundación Universitaria Española.

Astrana Marín, L. (1952³), F. de Quevedo Villegas, Obras completas, Obras en verso, Madrid, Aguilar.

Belleau, R. (1556), Les Odes d'Anacréon Teien, traduites de Grec en François, Par Remi Belleau de Nogent, París, André Wechel.

BÉnichou-Roubaud, S. (1960), «Quevedo helenista (el Anacreón castellano)», NRFH, XIV, 1-2: 51-72.

Brioso SÁnchez, M. (1970), Anacreontea. Un ensayo para su datación, Salamanca, Consejo Superior de Investigaciones Científicas, Colegio Trilingüe de la Universidad.

BRUNCK, R. F. P. (1786), Anacreontis Carmina. Accedunt selecta quaedam e lyricorum reliquiis. Editio nova locupletior, Estrasburgo, J. G. Treuttel.

Cacho Casal, R. (2003), La poesía burlesca de Quevedo y sus modelos italianos, Santiago de Compostela, Universidade.

Castanien, D. G. (1958), «Quevedo’s Anacreón castellano», Studies in Philology, LV, 4: 568-569.

Colomiès, P. (1669), Opuscula, Utrecht, Petrus Elzevirius.

Covarrubias, S. de (1943), Tesoro de la lengua castellana o española, según la impresión de 1611, con las adiciones de Benito Noydens publicadas en la de 1674, ed. Martín de Riquer, Barcelona, S. A. Horta.

Degen, J. F. (180833), Anacreontis Carmina, Erlangen, Gredius et Breuningius.

Dryden, J. (1961), Essays, vol. I, ed. W. P. Ker, Nueva York, Russell \& Russell.

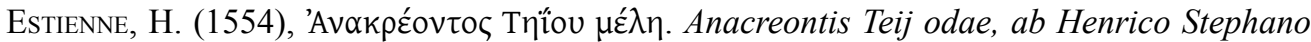
luce \& Latinitate nunc primum donatae, París, Henricus Stephanus.

- (1560), Pindari Olympia, Pythia, Nemea, Isthmia. Caeterorum octo Lyricorum carmina, s.l. [París], Henricus Stephanus.

- (1579), Theocriti aliorumque poetarum Idyllia, s.l. [París], Henricus Stephanus.

- (1604), Homeri Poemata duo, s.l. [Ginebra], Paulus Stephanus.

Fawkes, F. (1760), The Works of Anacreon, Sappho, Bion, Moschus and Musaeus. Translated from the original Greek, Londres, J. Newbery.

Fernández Mosquera, S. (1999), La poesía amorosa de Quevedo. Disposición y estilo desde "Canta sola a Lisi”, Madrid, Gredos.

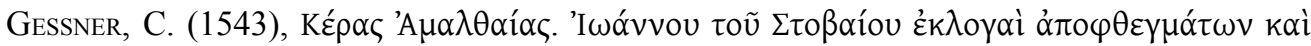

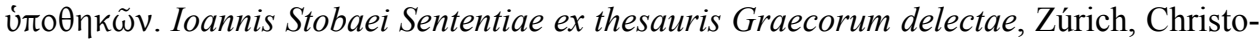
phorus Froschoverus.

Heinsius, D. (1600), Silio Itálico, De secundo Bello punico, Leiden, Ex officina Plantiniana apud Christophorum Raphelengium.

Hernando, C. (1975), Helenismo e Ilustración (El griego en el siglo XVIII español), Fundación Universitaria Española, Seminario Diego Hurtado de Mendoza, Madrid.

Hoven, R. (1994), Lexique de la prose latine de la Renaissance, Leiden / Nueva York / Colonia, Brill.

Jauralde Pou, P., «Cerrar podrá mis ojos la postrera...», RFE, LXXVII, 1-2: 89-117.

LIDA, M. R. (1939), «Para las fuentes de Quevedo», RFH, I, 4: 368-375.

Lindeman, Y. (1981), «Translation in the Renaissance: A Context and a Map», CRCL, VIII, 2: 204-216

Lipsius, J. (1585) Antiquae lectiones, en Opera omnia, vol. II, Amberes, Christophorus Plantinus. 
LóPez Eire, A. (1982), «La traducción de Quevedo del Manual de Epicteto», en V. García de la Concha (ed.), Homenaje a Quevedo (Actas de la II Academia Literaria Renacentista, Universidad de Salamanca, 10, 11 y 12 de diciembre, 1980), Salamanca, Universidad: 233-243.

López Grigera, L. (1998), Anotaciones de Quevedo a la Retórica de Aristóteles, Salamanca, ed. de la autora.

Mander, K. van (1604 [1969]), Het Schilder-Boeck, Haarlem, Paschier van Wesbuch [repr. Utrecht, Davaco].

Manrique, J. (1993), Poesía, ed. Vicente Beltrán, Barcelona, Crítica.

Menéndez Pelayo, M. (1953), Obras completas, vol. LVII: Biblioteca de traductores españoles, vol. IV (Oliver-Vives), ed. E. Sánchez Reyes, Santander, Aldus / Consejo Superior de Investigaciones Científicas.

Michelangeli, L. A. (1882), Anacreonte, Bolonia, Nicola Zanichelli.

Moya del Baño, F. (2006a), "Catulo, Ovidio y Propercio en el Anacreón de Quevedo», en E. Calderón, A. Morales y M. Valverde (eds.), KoINòs LóGOS. Homenaje al profesor José García López, Murcia, Universidad: 699-711.

- (2006b), “"Con pocos pero doctos”: Quevedo espejo de los clásicos», en A. Alvar Esquera (ed.), Actas del XI Congreso Español de Estudios Clásicos, vol. III, Madrid, Sociedad Española de Estudios Clásicos, 2006: 345-417.

- (2006c), «Petronio en Quevedo», Myrtia, 21: 277-296.

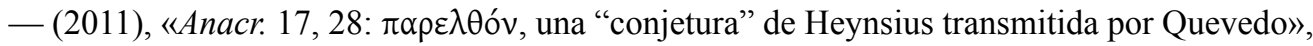
Myrtia, 26: 319-328.

O'Brien, J. (1995), Anacreon Redivivus. A Study of Anacreontic Translation in Mid-SixteenthCentury France, Ann Arbor, University of Michigan.

Olivares, J. (1995), La poesía amorosa de Quevedo. Estudio estético y existencial, Madrid, Siglo Veintiuno.

Pacheco, F. (2001²), El arte de la pintura, ed. Bonaventura Bassegoda i Hugas, Madrid, Cátedra.

Pauw, J. C. de (1732), Anacreontis Teii Odae et fragmenta, Graece et Latine, cum notis, Utrecht, Guilielmus Kroon.

Pérez CuencA, I. (2003), «Las lecturas de Quevedo a la luz de algunos impresos de su biblioteca», La Perinola, 7: 297-333.

PÉrez JimÉnez, A. (2011): «Sí, el Quevedo del Anacreón, helenista», en A. Pérez Jiménez y P. Volpe Cacciatore (eds.), "Musa Graeca Tradita, Musa Graeca Recepta». Traducciones de poetas griegos (Siglos XVI-XVII), Zaragoza, Pórtico, 2011: 103-130.

Quevedo, F. de $\left(1958^{4}\right)$, Obras completas, vol. I: Obras en prosa, ed. F. Buendía, Madrid, Aguilar.

- (1969), Obra poética, vol. I, ed. J. M. Blecua, Madrid, Castalia.

- $\left(1985^{2}\right)$, Obra poética, vol. IV: Teatro y traducciones poéticas, ed. J. M. Blecua, Madrid, Castalia.

- $\left(1968^{2}\right)$, Obras completas, vol. I: Poesía original, ed. J. M. Blecua, Barcelona, Planeta.

- (1999), Los sueños, ed. I. Arellano, Madrid, Cátedra.

Ramírez, A. (1966), Epistolario de Justo Lipsio y los españoles, 1577-1606, Madrid, Castalia. Rey, A. (1999²), Francisco de Quevedo, Poesía moral (Polimnia), Madrid, Támesis.

Rioja, F. de (1975), Versos, ed. G. Chiappini, Messina / Florencia, D’Anna.

Roig Miranda, Marie (2007), «Belleza y sentido: el caso de "Cerrar podrá mis ojos...” (B1. 472), de Quevedo», en Beatriz Mariscal (ed.), Actas del XV Congreso de la Asociación 
Internacional de Hispanistas, "Las dos orillas". Monterrey, México, del 9 al 24 de julio de 2004, vol. II: Literatura española y novohispana, siglos XVI, XVII y XVIII, arte y literatura, México, Fondo de Cultura Económica / Asociación Internacional de Hispanistas / Tecnológico de Monterrey / El Colegio de México, 2007: 509-520.

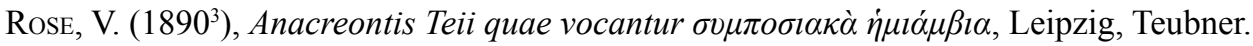

Rosenmeyer, P. A. (1992), The Poetic of Imitation. Anacreon and the Anacreontic Tradition, Cambridge, Cambridge UP.

Rubió y Lluch, A. (1879), Estudio crítico-bibliográfico sobre Anacreonte y la colección anacreóntica, y su influencia en la literatura antigua y moderna, Tesis Doctoral, Barcelona, Viuda e Hijos de J. Subirana.

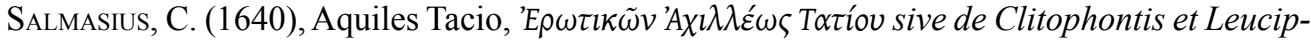
pes amoribus libri VII, Leiden, Franciscus Hegerus.

Scaligerus, J. C. (1561), Poetices libri septem, s.l. [Lyon], Antonius Vincentius.

- (1566), Commentarii, et animadversiones in sex libros De Causis plantarum Theophrasti, s.l. [Ginebra], Ioannes Crispinus.

- (1600), Poemata omnia, Pars Prima, s.l. [Heidelberg], In Bibliopolio Commeliniano.

Schоттus, A. (1610), Tullianarum Quaestionum, De instauranda Ciceronis Imitatione libri IIII, Amberes, Ex officina Plantiniana.

Schwartz, L. (1999), «Un lector áureo de los clásicos griegos: de los epigramas de la Antología griega a las Anacreónticas en la poesía de Quevedo», La Perinola. Revista de Investigación Quevediana, 3: 293-324.

- (2001), «El Anacreón castellano de Quevedo y las Eróticas de Villegas: lecturas de la poesía anacreóntica en el siglo XVII», en J. M. de Bernardo Ares (ed.), El hispanismo anglonorteamericano. Aportaciones, problemas y perspectivas sobre historia, arte y literatura españolas (siglos XVI-XVIII), Actas de la I Conferencia Internacional "Hacia un Nuevo Humanismo”. C.I.N.HU., Córdoba, 9-14 de septiembre de 1997, vol. II, Córdoba, Publicaciones obra social y cultural Cajasur: 1171-1201.

Shakespeare, W. (1990), The Complete Works (Compact Edition), eds. Stanley Wells y Gary Taylor, Oxford, Clarendon.

Sidney, Ph. (1985), The Countess of Pembroke's Arcadia (The Old Arcadia), ed. Katherine Duncan-Jones, Oxford, Oxford UP.

Sowerby, R. (1996), «The Homeric Versio Latina», ICS, XXI: 161-202.

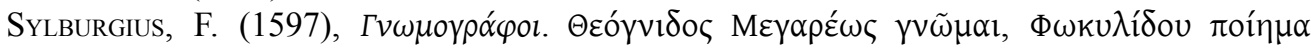

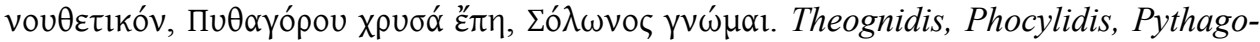
rae, Solonis et aliorum poemata gnomica, Heidelberg, Hieronymus Commelinus.

VegA, F. L. de (1609), Jerusalén conquistada, Madrid, Juan de la Cuesta.

Villegas, E. M. de (1941), Eróticas o amatorias, ed. Narciso Alonso Cortés, Madrid, EspasaCalpe.

Vives, J. L. (1782), Opera omnia, vol. II, Valencia, Benedictus Monfort.

West, M. L. (1984), «Problems in the Anacreontea», CQ, 34, 1: 206-221.

- $\left(1993^{2}\right)$, Carmina Anacreontea, Leipzig, Teubner.

Winshemius, V. (1558), Interpretatio Eidylliorum Theocriti, Frankfurt, Petrus Brubachius. 